\title{
The relationship between anticyclonic anomalies in northeastern Asia and severe haze in the Beijing-Tianjin-Hebei region
}

\author{
Wogu Zhong ${ }^{1,2}$, Zhicong Yin ${ }^{1,2}$, and Huijun Wang ${ }^{1,2}$ \\ ${ }^{1}$ Key Laboratory of Meteorological Disaster, Ministry of Education/Joint International Research Laboratory of Climate and \\ Environment Change (ILCEC)/Collaborative Innovation Center on Forecast and Evaluation of Meteorological Disasters \\ (CIC-FEMD), Nanjing University of Information Science and Technology, Nanjing 210044, China \\ ${ }^{2}$ Nansen-Zhu International Research Centre, Institute of Atmospheric Physics, Chinese Academy of Sciences, \\ Beijing 100029, China
}

Correspondence: Zhicong Yin (yinzhc@163.com)

Received: 30 July 2018 - Discussion started: 25 October 2018

Revised: 20 January 2019 - Accepted: 23 March 2019 - Published: 6 May 2019

\begin{abstract}
Haze pollution in the Beijing-Tianjin-Hebei (BTH) region has become increasingly more severe and persistent in recent years. To better understand the formation of severe haze and its relationship with anticyclonic anomalies over northeastern Asia (AANA), this research focused on severe haze over the BTH region occurring in December during 2014-2016 and examined the impacts of AANA. The results indicated that local meteorological conditions were conducive to severe haze (such as weaker surface winds, a stronger temperature inversion, a shallower boundary layer, and higher relative humidity) and were all closely related to AANA. During severe haze episodes, AANA remained strong in the middle upper troposphere, generating anomalous southeasterly winds near the surface. This effect not only promoted the accumulation of pollutants due to the unique topographical conditions in the BTH region but also caused warm advection in lower levels, which was the main cause of the formation and development of a temperature inversion layer. As a synoptic-scale circulation, AANA were accompanied by anomalous vertical motions in the surrounding areas, which weakened the meridional circulation over the BTH region. Intrusions of clean air from upper levels to the surface and downward transport of westerly momentum at mid-levels and upper levels were suppressed, resulting in weaker northerly winds near the surface and a shallower boundary layer. The thermally indirect zonal circulation between the BTH region and western Pacific triggered by AANA provided a persistent source of moisture for the BTH region, which strengthened the development of severe
\end{abstract}

haze by promoting the growth of fine particulates. The advance and retreat of AANA often corresponded with the emergence and dissipation of severe haze, illustrating that AANA could be effective forecast indicators for air quality.

\section{Introduction}

Haze is a weather phenomenon that can restrict visibility and increase the risk of traffic accidents, and haze is also a type of serious air pollution that is detrimental to people's health (Hu et al., 2015; Wang et al., 2016). Haze events in China are mainly caused by fine particulate matter (with a diameter less than $2.5 \mu \mathrm{m} ; \mathrm{PM}_{2.5}$ ), which contains primary pollutants and sulfate or nitrate aerosols (Wang et al., 2016; Cai et al., 2017; Shen et al., 2018). In recent years, the Beijing-TianjinHebei (BTH, located at $\left.36-42^{\circ} \mathrm{N}, 114-120^{\circ} \mathrm{E}\right)$ region has witnessed several severe haze events with long durations, large spatial extents, and serious pollution levels. Notably, the number of haze days in the BTH region has increased, and the affected area has shown an inter-decadal expanding trend (Zhang et al., 2015). To control air pollution, the Chinese government enacted the Air Pollution Prevention and Control Action Plan in 2013. So far, the atmospheric environment quality in the BTH region has improved to a certain extent, mainly via a reduction in $\mathrm{SO}_{2}$ and $\mathrm{NO}_{2}$ concentrations ("Formation Mechanism and Control Strategies of Haze in China" professional group, 2015). However, a corresponding decline in $\mathrm{PM}_{2.5}$ concentration was not obvious, and the 
occurrence of severe haze events in the BTH region showed strong interannual variation, especially in winter (Chen and Wang, 2015; Yin and Wang, 2018). Previous studies have suggested that the strong interannual variation in December haze days is different from that in other winter months (Yin and Wang, 2018). During 16-21 December 2016, the BTH region suffered serious air pollution. Despite more than 30 cities initiating an air pollution red alert ahead of time, the pollution lasted for $5 \mathrm{~d}$, and the instantaneous $\mathrm{PM}_{2.5}$ concentration reached up to $1000 \mu \mathrm{g} \mathrm{m}^{-3}$ in Shijiazhuang, the capital of Hebei province. Another pollution event occurred from 30 December 2016 to 7 January 2017, lasting for as long as $9 \mathrm{~d}$. The occurrence of two long-term severe haze episodes within $20 \mathrm{~d}$ of each other triggered a broader discussion about their formation, scientific attribution, and reasonable methods of management (Wang, 2018).

Previous studies have indicated that the formation of severe haze is characterized by a complex interplay between anthropogenic emissions, chemical processes, and meteorological factors (Wang et al., 2016; Tang et al., 2018). The basic cause of haze pollution is excessive emissions (Wang et al., 2013; Zhang et al., 2013). The synergistic effects of these anthropogenic emissions may worsen air pollution in northern China (Wang et al., 2016; Yang et al., 2016). Nevertheless, meteorological conditions still play a key role in the formation of haze events (Zhang et al., 2014; Yin et al., 2017; Wei et al., 2017). According to recent research (Cai et al., 2017), atmospheric circulation changes induced by global warming may enhance the stability of the lower atmosphere in Beijing, leading to more frequent and severe haze pollution in the future. Furthermore, the decline of autumn Arctic sea ice and the negative anomalies in subtropical western Pacific sea surface temperature could greatly change the atmospheric circulation and lead to an increase in haze days in eastern China (Wang et al., 2015; Yin and Wang, 2016). Haze pollution could be exacerbated under these forcing factors through its impact on atmospheric circulation and meteorological conditions. In addition, local meteorological conditions and the structure of the boundary layer will vary with the change in the large-scale circulation conditions, which could affect the dispersion capability of the atmosphere and thus have an effect on air pollution (Wu et al., 2017). The weather conditions affecting pollutant dispersion include dynamic factors (e.g., wind and turbulence) and thermodynamic factors (e.g., atmospheric stratification and its stability) (Zhang et al., 2014). Lower wind speed, higher relative humidity, and stable atmospheric stratification are the main factors conducive to the occurrence of haze (Zhang et al., 2014; Ding and Liu, 2014; Yin et al., 2015b). Such weather conditions could be strengthened by a weaker East Asian winter monsoon (EAWM) and the positive phase of the East Atlantic-West Russia (EA/WR) teleconnection (Yin et al., 2015a; Wu et al., 2016; Yin and Wang, 2016).

Research on persistent and severe haze pollution in the BTH region has demonstrated that anticyclonic anomalies in northeastern Asia (AANA) represent a key local circulation that is conducive to the formation of serious haze pollution (Yin and Wang, 2016, 2017, 2018; Yin et al., 2017). Some studies have indicated that a weak EAWM could modulate AANA ( $\mathrm{Li}$ et al., 2015; Yin et al., 2015a). With the decline of EAWM, cold air is restricted to high-latitude areas, and the East Asian trough becomes weak. It is physically reasonable that the weaker East Asian trough appears as an anticyclonic circulation in the anomaly field. Thus, to some extent, AANA are a representative indicator of the EAWM system (Wang and Jiang, 2004). However, it is still unclear how such atmospheric anomalies affect the occurrence of severe haze events. To better represent the intensity of AANA and their physical impact on haze pollution, we defined $\mathrm{AANAI}_{Z_{500}}\left(\mathrm{AANAI}_{\omega_{500}}\right)$ and $\mathrm{AANAI}_{V_{850}}$ according to anomalies in the $500 \mathrm{hPa}$ geopotential height (vertical velocity) field and $850 \mathrm{hPa}$ wind field composited during severe haze episodes, referring to previous EAWM indices (Wang and Jiang, 2004; He and Wang, 2012). Considering that the air quality measurement network in China was developed relatively recently, this study focuses on severe haze pollution in the BTH region during December in the years 2014-2016 and explicates the characteristics of AANA and their relationship with severe haze while making a comparison with non-haze episodes. The situation in December 2017 was also discussed to verify the relationship revealed in this study.

\section{Data and method}

Meteorological observation data for December in the years 2014-2017 were obtained at $3 \mathrm{~h}$ intervals from the China Meteorological Administration, including visibility, surface wind speed, and surface relative humidity (RH). Hourly $\mathrm{PM}_{2.5}$ concentration data from 80 national air quality stations over the BTH region were derived from the website of the China National Environmental Monitoring Centre (2018). Additionally, the geopotential height at $500 \mathrm{hPa}$; sea level pressure (SLP); $U$ and $V$ components of wind at $200,850 \mathrm{hPa}$, and the surface; vertical velocity (omega) from 200 to $1000 \mathrm{hPa}$; temperature at $850,1000 \mathrm{hPa}$, and the surface; surface dew point temperature; RH from 200 to $1000 \mathrm{hPa}$; and planetary boundary layer height (PBLH) from the ERA-Interim reanalysis data (Dee et al., 2011; ERAInterim, 2019) were downloaded from the European Centre for Medium-Range Weather Forecasts (ECMWF), with a horizontal resolution of $0.75^{\circ} \times 0.75^{\circ}$. The surface $\mathrm{RH}$ field was calculated based on the surface temperature and the dew point temperature taken from the ERA-Interim reanalysis data. Considering that ERA-Interim might have problems capturing the day-to-day and diurnal variations in PBLH over northern China (von Engeln and Teixeira, 2013; Guo et al., 2016), the National Centers for Environmental Prediction (NCEP) operational Global Data Assimilation System/Final (GDAS/FNL) surface flux data (NCEP, 2019) were applied 
to make a comparison. Anomaly fields were calculated with respect to the mean climatology in December from 1979 to 2010. Considering the strong diurnal variations in some meteorological factors, such as the PBLH, temperature, and $\mathrm{RH}$, the climatologies were calculated separately for 02:00, 08:00, 14:00, and 20:00, Beijing local time.

Considering that national air quality stations over the BTH region are scarce and unevenly distributed, we used Thiessen polygons here to calculate the weighted average of $\mathrm{PM}_{2.5}$ concentration and built time series at $6 \mathrm{~h}$ intervals. Following this, we selected the severe haze events (defined as $\mathrm{PM}_{2.5}$ concentration $\geq 150 \mu \mathrm{g} \mathrm{m}^{-3}$; Cai et al., 2017) and non-haze events $\left(\mathrm{PM}_{2.5}\right.$ concentration $\left.\leq 50 \mu \mathrm{g} \mathrm{m}^{-3}\right)$ and used composite analysis to analyze the associated atmospheric circulations and weather conditions. Most previous studies have investigated haze events in units of hours or days, and the variations among different haze episodes were not taken into account. Some meteorological factors might be closely related to haze pollution in a few cases but remain insignificant in others. In this way, relationships between haze pollution and meteorological factors might be overemphasized. Meanwhile, some meteorological factors, such as the PBLH and RH, show strong temporal variations that might call their statistical relationship with haze pollution into question. Thus, neglecting the small timescale disturbances within each synoptic-scale environment could help to deepen insight into the physical relationship (Lackmann, 2011). To better describe the relationships and mechanisms manifesting among different haze episodes, a new data field called synoptic-process mean (SPM) data was calculated. According to the $\mathrm{PM}_{2.5}$ concentration, the synopticscale environments were divided into three groups: severe haze, non-haze, and non-severe haze (i.e., $\mathrm{PM}_{2.5}$ concentration $\in[50,150] \mu \mathrm{g} \mathrm{m}^{-3}$ ). Two criteria were used to ensure that each type of haze episode was representative and mutually independent: (1) a haze episode should have a minimum duration of at least $12 \mathrm{~h}$ (i.e., two time steps; a time step represents $6 \mathrm{~h}$ ) and (2) if any two haze episodes of the same type were detected within $24 \mathrm{~h}$ (i.e., four time steps), these two episodes would be merged into one. The SPM data applied time averaging to calculate mean $\mathrm{PM}_{2.5}$ concentrations and meteorological variables during each haze episode. Based on the SPM data, synoptic-process correlation coefficients (SPCCs) were calculated in units of haze episodes, rather than in units of hours or days. This method maintains the physical relations between haze and meteorological factors while removing the potential influence of day-to-day and diurnal variations inside each synoptic-scale environment. In addition, the vertical transport of westerly momentum was defined as $\frac{\partial u \omega}{\partial P}$ in this study (Zhong et al., 2010). $\frac{\partial u \omega}{\partial P}<0$ represents a downward transport of westerly momentum and $\frac{\partial u \omega}{\partial P}>0$ represents an upward transport of westerly momentum (i.e., downward transport was restricted).

\section{Results}

Figure 1 shows the 6-hourly variation in $\mathrm{PM}_{2.5}$ concentration over the BTH region in December 2014, December 2015, and December 2016. The monthly mean concentrations in 20142016 were $84.7,126.4$, and $128.1 \mathrm{\mu g} \mathrm{m}^{-3}$, and the standard deviations were $55.4,79.1$, and $70.9 \mu \mathrm{g} \mathrm{m}^{-3}$, respectively. These results demonstrated that haze pollution in December was often serious, with large fluctuations. The first and third quartiles of the series were 54.0 and $156.7 \mu \mathrm{g} \mathrm{m}^{-3}$, indicating that the threshold values of severe haze $\left(150 \mu \mathrm{g} \mathrm{m}^{-3}\right)$ and non-haze $\left(50 \mu \mathrm{g} \mathrm{m}^{-3}\right)$ events were reasonable. There were 14 severe haze and 12 non-haze events in December in the years 2014-2016 (Table 1). The duration time of severe haze events (9.3 time steps) was relatively long compared to nonhaze events (8.9 time steps), especially in 2015 and 2016. With respect to the severe haze since 15 December 2016 , most cities in the BTH region and surrounding areas issued an air pollution red alert ahead of time, and anthropogenic emissions were strictly controlled. Despite those efforts, the $\mathrm{BTH}$ region still experienced serious and persistent haze, demonstrating that meteorological conditions had a significant impact on haze pollution (Yin and Wang, 2017).

As a critical system influencing the climate pattern over East Asia, the EAWM plays an important role in the formation of severe haze (Zhang et al., 2014; Yin et al., 2015a; Yin and Wang, 2017). When severe haze occurred, the EAWM weakened throughout the troposphere, as indicated by the relatively low geopotential heights over Siberia and the Aleutian Islands at mid-levels (Fig. 2a), a decline in northerly winds near the surface (Fig. 3a-b), and a warmer land surface (Fig. 2b). As a consequence, the East Asian jet stream was weaker and moved northward with respect to the climatological mean (Yin and Wang, 2017), while the East Asian trough weakened and moved eastwards (Fig. 2a). These results indicated that the meridional circulation over midlatitude and high-latitude areas in East Asia was weakened during severe haze events so that the $\mathrm{BTH}$ region was mainly covered by zonal circulation. Thus, cold-air intrusions and their southward movement into the BTH region were suppressed (Chen and Wang, 2015; Yin and Wang, 2017). Negative anomalies in SLP were obvious over the midlatitude and high-latitude areas of the Eurasian continent, with two negative centers located over the Siberian plain and Bering Strait, while the SLP anomaly in the western Pacific was positive (Fig. 2b). The change in land-sea contrast implies southeasterly winds. Considering that the $\mathrm{BTH}$ region is located southeast of the Taihang-Yanshan Mountains, southeasterly wind anomalies tend to restrict the dispersion of pollutants. Moreover, the warm air brought by the southeasterly winds increased the temperature inversion potential (TIP, $T_{850}-T_{1000}$ ). The enhancement of stable stratification restricted the vertical dispersion of pollutants (Fig. 3a). By contrast, during non-haze events the EAWM was relatively strong in the troposphere (Fig. 2c-d). Thus, cold-air incursions were more frequent, re- 


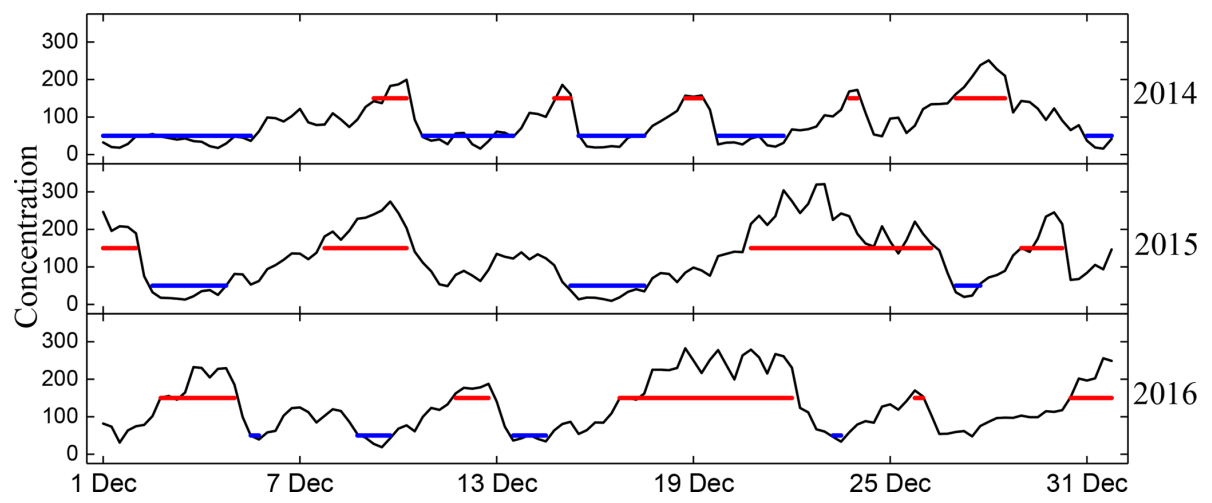

Figure 1. The 6-hourly variations in mean $\mathrm{PM}_{2.5}$ concentration over the BTH region (units: $\mu \mathrm{g} \mathrm{m}^{-3}$ ) in December 2014, December 2015, and December 2016. The periods (concentrations) corresponding to the red or blue lines indicate the occurrence (threshold values) of severe haze or non-haze episodes, respectively.

Table 1. The timetable of 14 severe haze and 12 non-haze episodes. The severe haze episodes are marked by bold font. The unit of the $\mathrm{PM}_{2.5}$ concentration is $\mu \mathrm{g} \mathrm{m}^{-3}$. The start time and end time are listed in Beijing local time. The numeral before the time indicates the day in December on which each episode occurred.

\begin{tabular}{|c|c|c|c|c|c|c|}
\hline Year & Start time & End time & $\begin{array}{r}\text { Mean } \\
\text { concentration }\end{array}$ & Start time & End time & $\begin{array}{r}\text { Mean } \\
\text { concentration }\end{array}$ \\
\hline \multirow[t]{5}{*}{2014} & $108: 00$ & $514: 00$ & 36.69 & 18 20:00 & 19 08:00 & 156.22 \\
\hline & 9 08:00 & 10 08:00 & 169.70 & 19 20:00 & 21 20:00 & 31.62 \\
\hline & 10 20:00 & $1314: 00$ & 42.52 & 23 20:00 & 24 02:00 & 170.25 \\
\hline & 14 20:00 & 15 08:00 & 163.05 & 27 02:00 & 28 14:00 & 210.76 \\
\hline & 15 14:00 & $1714: 00$ & 33.32 & 31 02:00 & 31 20:00 & 28.21 \\
\hline \multirow[t]{4}{*}{2015} & 1 08:00 & $202: 00$ & 200.11 & 20 20:00 & 26 08:00 & 221.44 \\
\hline & $214: 00$ & $420: 00$ & 26.37 & 27 02:00 & 27 20:00 & 32.55 \\
\hline & $720: 00$ & 10 08:00 & 219.65 & 29 02:00 & 30 08:00 & 193.29 \\
\hline & 15 08:00 & 17 14:00 & 23.74 & & & \\
\hline \multirow[t]{5}{*}{2016} & 2 20:00 & 5 02:00 & 192.60 & 16 20:00 & 22 02:00 & 227.48 \\
\hline & $514: 00$ & $520: 00$ & 44.17 & 23 08:00 & $2314: 00$ & 39.75 \\
\hline & 8 20:00 & $920: 00$ & 37.24 & 25 20:00 & 26 02:00 & 162.07 \\
\hline & $1120: 00$ & 12 20:00 & 175.91 & 30 14:00 & 31 20:00 & 209.76 \\
\hline & $1314: 00$ & 14 14:00 & 40.82 & & & \\
\hline
\end{tabular}

sulting in stronger surface winds and lower surface $\mathrm{RH}$ in the BTH region (Fig. 3c-d). In addition, the pressure difference between the western Pacific and the BTH region increased and the northerly winds strengthened, aiding the dispersion of $\mathrm{PM}_{2.5}$. In general, a weakening of the EAWM restricts cold-air incursions and impacts local weather conditions, including surface wind speeds, surface RH, and TIP, whose SPCCs with mean $\mathrm{PM}_{2.5}$ concentration in the $\mathrm{BTH}$ region were $-0.42,0.72$, and 0.56 , respectively, all exceeding the $99 \%$ confidence level (Table 2). With the decline in wind speed near the surface and the increase in TIP, the horizontal and vertical dispersion of pollutants was inhibited, while higher surface RH exacerbated the formation of particulates. These factors led to a rapid increase in $\mathrm{PM}_{2.5}$ concentration and resulted in severe haze (Fig. 4).
The aforementioned southeasterly wind, abundant moisture, and strong temperature inversion that induced severe haze were all closely related to AANA (Figs. 4-5). Thus, we hypothesize that AANA are a key circulation pattern influencing severe haze in the BTH region. Here, we defined three indices: $\mathrm{AANAI}_{Z_{500}}$ (defined as $Z_{500}$ anomalies over $30-50^{\circ} \mathrm{N}, 115-140^{\circ} \mathrm{E}$; white box in Fig. 2a), AANAI $V_{850}$ (defined as wind speed anomalies at $850 \mathrm{hPa}$ over $30-40^{\circ} \mathrm{N}$, $120-150^{\circ} \mathrm{E}$; black box in Fig. 3a), and AANAI $_{\omega_{500}}$ (defined as $\omega_{500}$ anomalies over $35-45^{\circ} \mathrm{N}, 115-125^{\circ} \mathrm{E}$; white box in Fig. 6a) to describe the intensity of AANA in the middle and lower troposphere. Note that the AANAI $Z_{500}$ and $\mathrm{AANAI}_{V_{850}}$ are similar to previous EAWM indices (Wang and Jiang, 2004; He and Wang, 2012), as AANA are an important manifestation of a weaker EAWM (Fig. 2a). However, we defined these indices here through anomaly fields to 

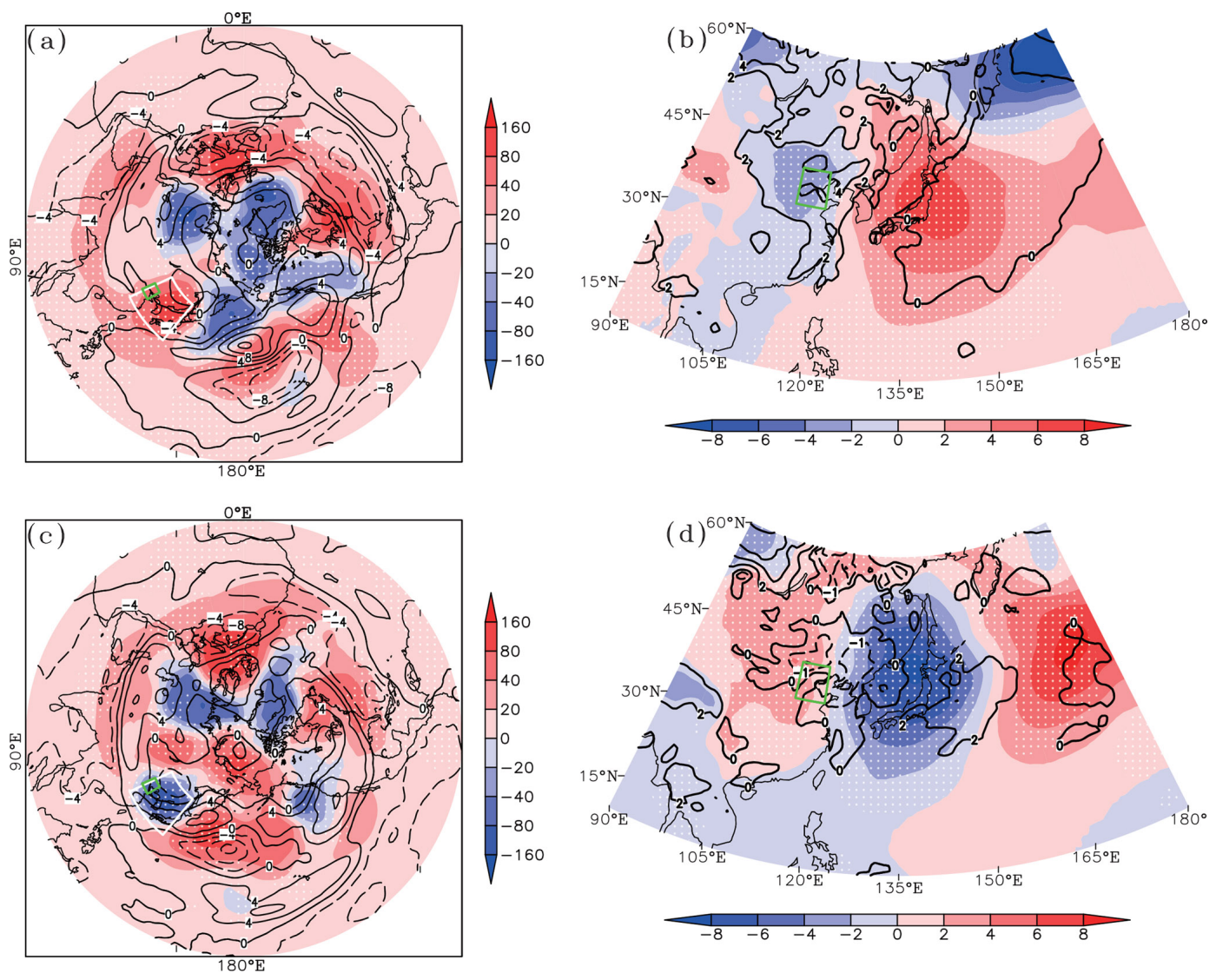

Figure 2. Composite distribution of atmospheric circulation anomalies during severe haze or non-haze episodes. Anomalies were calculated with respect to the 1979-2010 climatology. The green (white) box indicates the BTH region (the area covered by $\mathrm{AANAI}_{Z_{500}}$ ). (a) $Z_{500}$ (shading, units: geopotential meter, gpm) and $U_{200}$ (contour, units: $\mathrm{m} \mathrm{s}^{-1}$ ) during severe haze episodes; white dots indicate that $Z_{500}$ anomalies exceeded the $95 \%$ confidence level ( $t$ test). (b) SLP (shading, units: hPa) and surface air temperature (SAT; contour, units: K) during severe haze episodes; white dots indicate that SLP anomalies exceeded the $95 \%$ confidence level ( $t$ test). Panel (c) is the same as (a) but for non-haze episodes. Panel (d) is the same as (b) but for non-haze episodes.

Table 2. SPCCs between the mean $\mathrm{PM}_{2.5}$ concentration over the BTH region and key meteorological indices. All the SPCCs exceeded the $99 \%$ confidence level. Visibility, surface wind speed, and surface relative humidity (RH) were based on observed data and used to calculate the mean over the BTH region. Temperature inversion potential (TIP, defined as $T_{850}-T_{1000}$ ) anomalies were calculated as mean anomalies over the BTH region with respect to the 1979-2010 climatology. Planetary boundary layer height (PBLH) anomalies were calculated as mean anomalies over the BTH region with respect to the 1979-2010 climatology. Synoptic-process correlation coefficients (SPCCs) were calculated based on SPM data, aggregated by averaging mean $\mathrm{PM}_{2.5}$ concentrations, all meteorological data, and AANA indices during each severe haze (14), non-haze (12), and non-severe haze (24) episode. The total sample size was 50.

\begin{tabular}{rrrrrrrrr}
\hline Index & $\begin{array}{r}\text { AANA } \\
I_{Z_{500}}\end{array}$ & $\begin{array}{r}\text { AANA } \\
I_{V_{850}}\end{array}$ & AANAI $_{\omega 500}$ & Visibility & $\begin{array}{r}\text { Surface wind } \\
\text { speed }\end{array}$ & $\begin{array}{r}\text { Surface } \\
\text { RH }\end{array}$ & $\begin{array}{r}\text { TIP } \\
\text { anomalies }\end{array}$ & $\begin{array}{r}\text { ERA PBLH } \\
\text { anomalies }\end{array}$ \\
\hline SPCC & 0.64 & -0.64 & -0.70 & -0.83 & -0.42 & 0.72 & 0.56 & -0.60 \\
\hline
\end{tabular}

analyze anomalous atmospheric circulations, differing from the EAWM indices, which were used to describe the intensity of the EAWM and its climatic evolution. The physical meaning and the critical areas taken into account also differ between $\mathrm{AANAI}_{Z_{500}}\left(\mathrm{AANAI}_{V_{850}}\right)$ and related EAWM indices. Considering that the AANAI $Z_{500}$ and $\mathrm{AANAI}_{V_{850}}$ only represent the intensity of AANA in the horizontal dimension, we further introduced AANAI ${ }_{\omega 500}$ to investigate the vertical structure of AANA. This part will be illustrated in detail in the following section. We calculated the SPCC between area-mean $\mathrm{PM}_{2.5}$ concentrations in the $\mathrm{BTH}$ region and $\mathrm{AANAI}_{Z_{500}}\left(\mathrm{AANAI}_{V_{850}}\right)$ as $0.64(-0.64)$, exceeding the $99 \%$ confidence level (Table 2). Thus, changes in AANA were closely related to the emergence and development of 

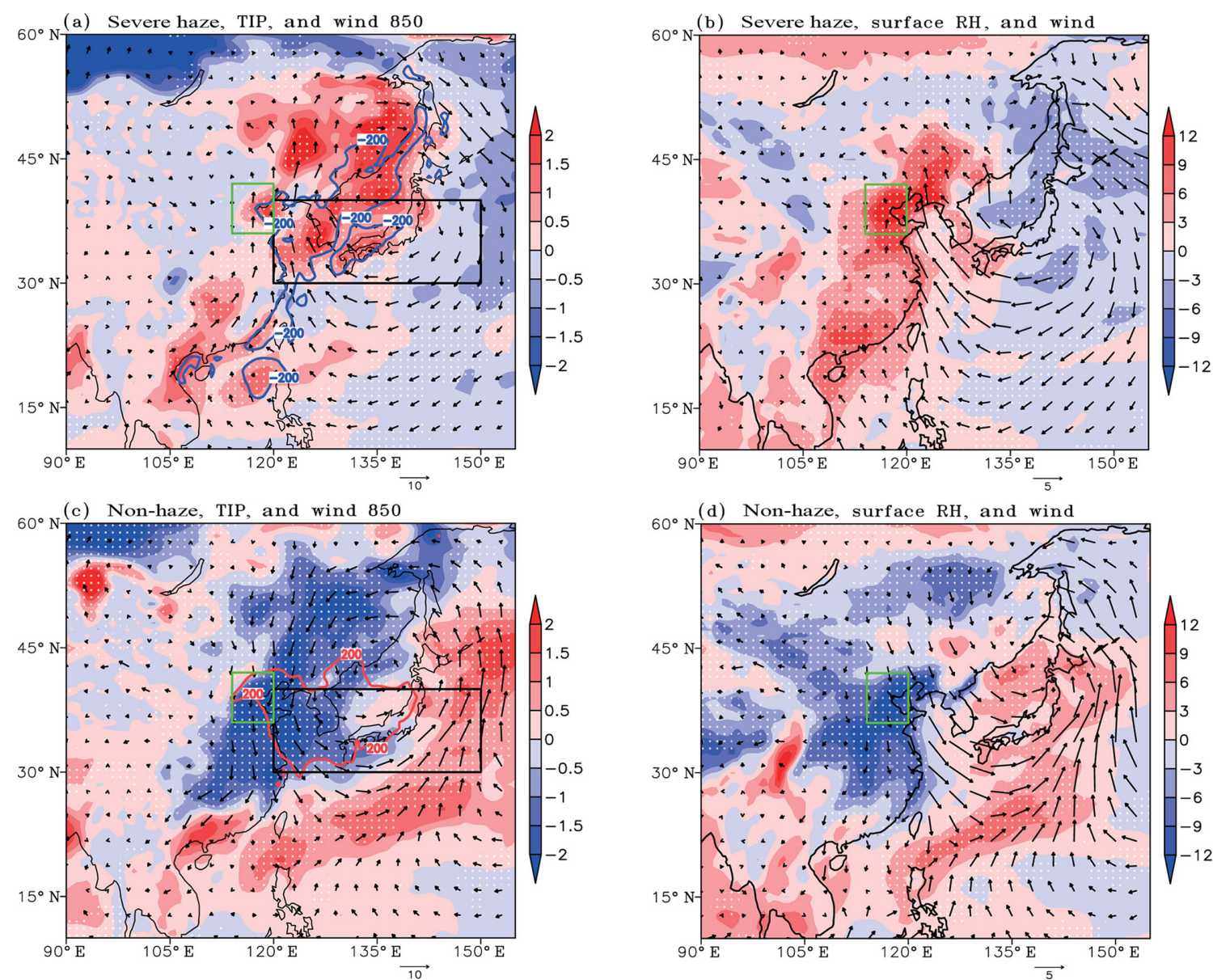

Figure 3. Composite distribution of local atmospheric circulation anomalies during severe haze or non-haze episodes. Anomalies were calculated with respect to the 1979-2010 climatology. The green (black) box indicates the BTH region (the area covered by AANAI $V_{850}$ ). (a) $V_{850}$ (arrow, units: $\mathrm{m} \mathrm{s}^{-1}$ ), PBLH (contour, units: $\mathrm{m}$ ), and temperature inversion potential (TIP, $T_{850}-T_{1000}$, shading, units: K) during severe haze episodes; the bold blue contours indicate that PBLH was more than $200 \mathrm{~m}$ below normal; white dots indicate that temperature inversion potential anomalies exceeded the $95 \%$ confidence level $\left(t\right.$ test). (b) Surface wind (arrow, units: $\mathrm{m} \mathrm{s}^{-1}$ ) and surface RH (shading, units: \%) during severe haze episodes; white dots indicate that surface RH anomalies exceeded the $95 \%$ confidence level ( $t$ test). Panel (c) is the same as (a) but for non-haze episodes; the bold red contours indicate that PBLH was more than $200 \mathrm{~m}$ above normal. Panel (d) is the same as (b) but for non-haze episodes.

haze pollution (Fig. 5). When severe haze took place, AANA were evident from the lower to the upper levels, especially in the middle troposphere (Fig. 6a). AANA were associated with southeasterly winds near the surface (Fig. 3a), which favored the accumulation of pollutants and water vapor. Southeasterly winds gathered pollutants from the surrounding areas and provided a steady supply of fine particulates and precursor species for haze pollution in the BTH region, while bringing moisture from the western Pacific to the BTH region via Bohai Bay. Weak convergence induced by the anomalous low surface pressure helped to import moisture into the BTH region (Fig. 3b). This promoted the hygroscopic growth of fine particulates and the formation of secondary pollutants (Wang et al., 2016). In addition, warm advection induced by southeasterly winds was prevalent in the middle and lower troposphere over the BTH region (Fig. 7). Strong warm advection at mid-levels is also consistent with a weaker EAWM. Specifically, local temperature increases generated by warm advection were stronger at $850 \mathrm{hPa}$ than those at $1000 \mathrm{hPa}$ on the day before the first day of severe haze events. Even though anomalous vertical motion had a negative effect on changes of temperature around the first day of severe haze events, the positive changes due to horizontal advection still prevailed in lower levels so that the local temperature tendencies remained positive (Fig. 7). These effects were propitious to the formation and development of a stronger temperature inversion and an increase in atmospheric stability (Fig. 3a). The SPCC between AANAI $Z_{500}$ and TIP was 0.58 , exceeding the $95 \%$ confidence level (Table 3 ). For non-haze events, northeastern Asia was mainly covered by cyclonic anoma- 


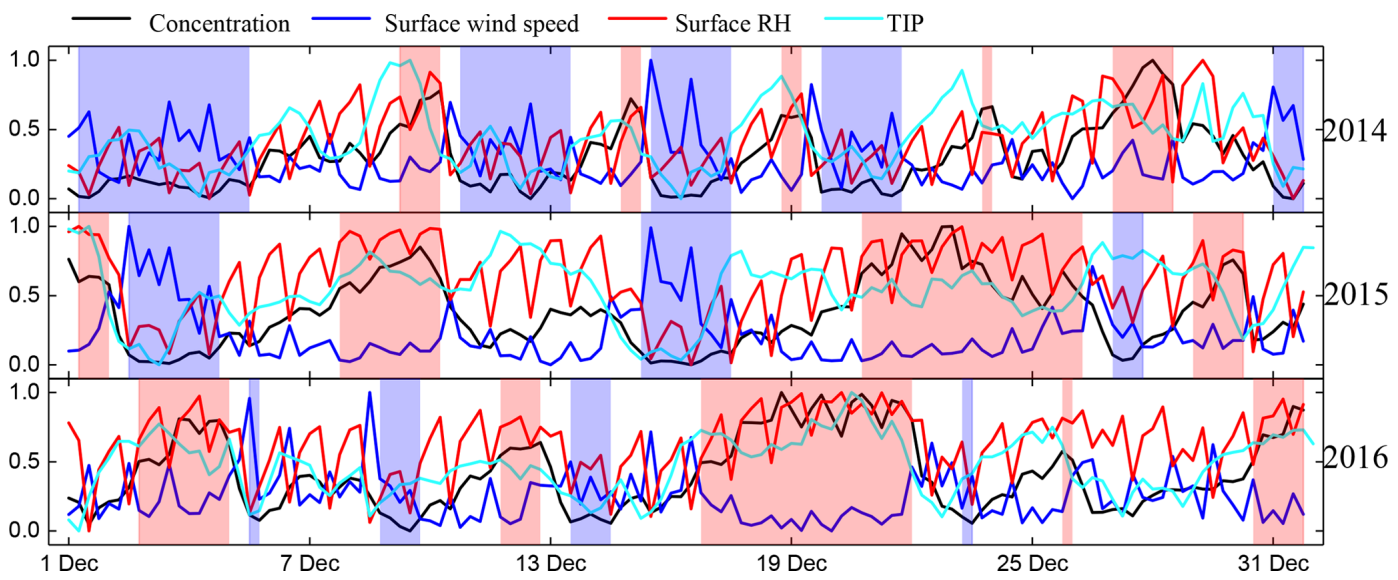

Figure 4. The 6-hourly variations in $\mathrm{PM}_{2.5}$ concentration, surface wind speed, surface RH, and TIP in December 2014, December 2015, and December 2016. All data were subjected to min-max normalization. Periods corresponding to areas of red (blue) shading indicate the occurrence of severe haze (non-haze) episodes. Note that each area of red or blue shading represents a synoptic process of severe haze or non-haze, respectively. Episodes between severe haze and non-haze episodes were defined as non-severe haze episodes, representing the normal situation. Synoptic-process mean (SPM) data were aggregated by averaging $\mathrm{PM}_{2.5}$ concentrations and all meteorological data during each episode.

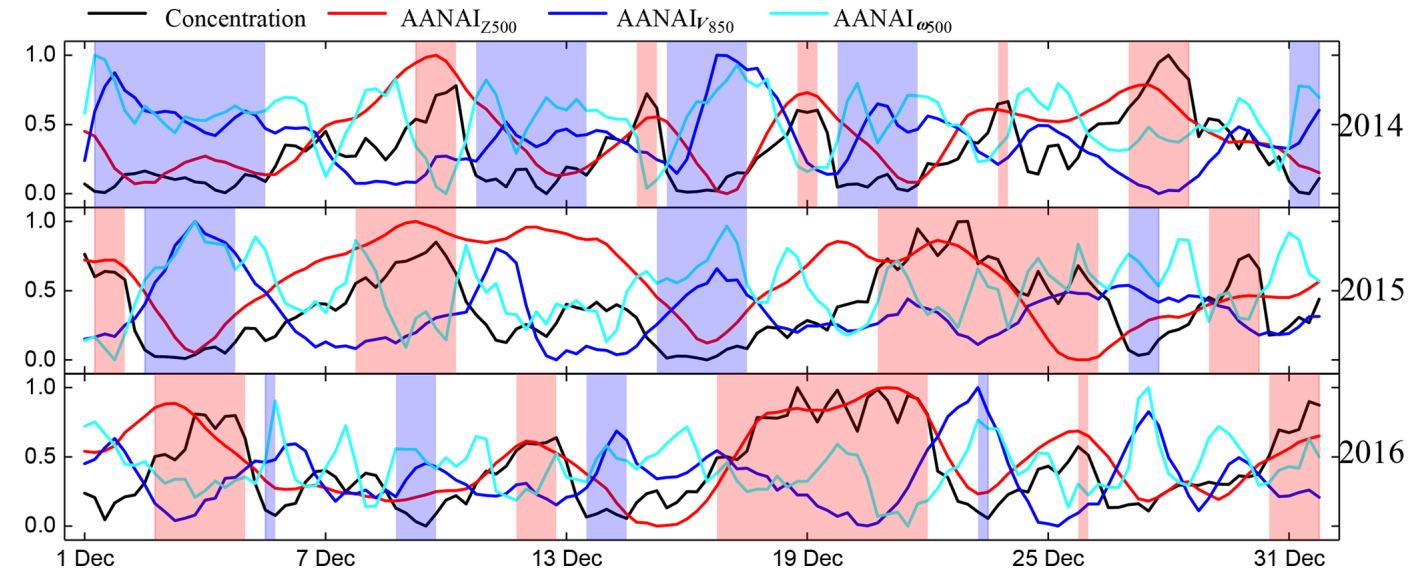

Figure 5. The 6-hourly variations in $\mathrm{PM}_{2.5}$ concentration, $\mathrm{AANAI}_{Z_{500}}, \mathrm{AANAI}_{V_{850}}$, and $\mathrm{AANAI}_{\omega_{500}}$ in December 2014, December 2015, and December 2016. Periods corresponding to areas of red (blue) shading indicate the occurrence of severe haze or (non-haze) episodes. Note that each area of red or blue shading represents a synoptic process of severe haze or non-haze, respectively. Episodes between severe haze and non-haze episodes were defined as non-severe haze episodes, representing the normal situation. Synoptic-process mean (SPM) data were aggregated by averaging mean $\mathrm{PM}_{2.5}$ concentrations and all AANA indices during each episode.

lies (Fig. 6b), which strengthened northerly winds near the surface (Fig. 3c). Strong northerly winds brought about cold advection over the BTH region and inhibited the transport of water vapor (Fig. 3d). Higher wind speeds and a drier atmosphere were conducive to the dispersion of pollutants. The SPCC between AANAI $Z_{500}$ and surface wind speed (surface $\mathrm{RH})$ was $-0.38(0.73)$, exceeding the $99 \%$ confidence level (Table 3). Thus, because of the unique topographical conditions in the BTH region, the anomalous southeasterly flow caused by AANA facilitated the formation and aggregation of haze particulates. The emergence of a temperature inversion layer enhanced the atmospheric stability, leading to more persistent and serious haze events. Aside from hori- zontal dispersion, vertical dispersion also played a vital role in haze pollution (Zhao et al., 2013; Wu et al., 2017). When severe haze occurred, negative anomalies of vertical velocity (omega) were common over northeastern Asia and the coastal regions of eastern China, while positive anomalies were mainly located over the northwestern Pacific (Fig. 6a). Thus, the mid-level reflection of AANA was accompanied by an anomalous synoptic-scale ascending motion to the rear (west) of AANA and an anomalous descending motion to the front (east) of AANA. The distribution of anomalies was the opposite during non-haze events: cyclonic anomalies appeared, with anomalous synoptic-scale ascending motions to the front (east) of the cyclonic anomalies and anomalous de- 
(a) Severe haze

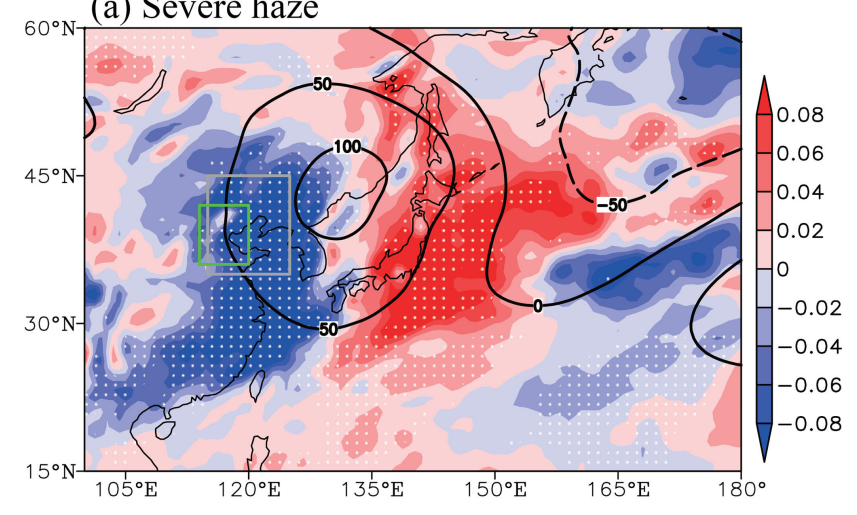

(b) Non-haze

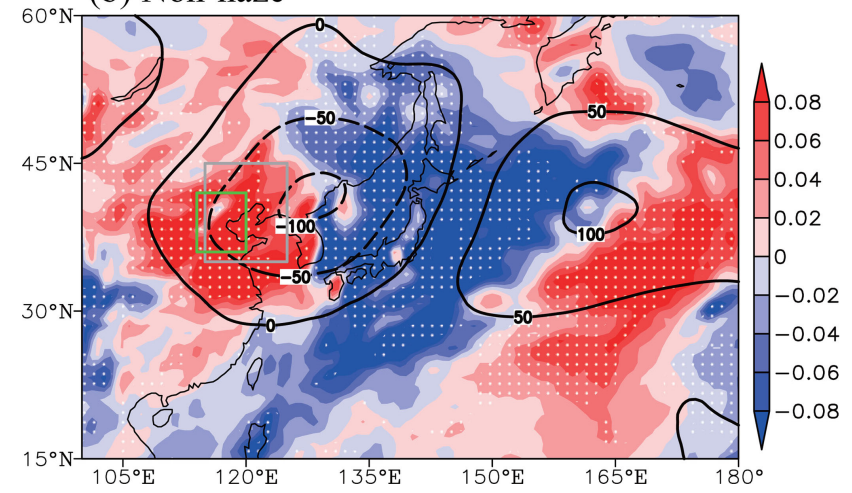

Figure 6. Structure of AANA in the middle troposphere: $Z_{500}$ (contour, units: gpm) and $\omega_{500}$ (shading, units: $\mathrm{Pa} \mathrm{s}^{-1}$ ). Anomalies were calculated with respect to the 1979-2010 climatology. The green (gray) box indicates the BTH region (the area covered by AANAI $_{(500}$ ). (a) Severe haze episodes and (b) non-haze episodes. White dots indicate that $\omega_{500}$ anomalies exceeded the $95 \%$ confidence level ( $t$ test).

scending motions to the rear (west) of the cyclonic anomalies (Fig. 6b). The SPCC between AANAI $\omega_{500}$ and the mean $\mathrm{PM}_{2.5}$ concentration in the BTH region was -0.70 , exceeding the $99 \%$ confidence level (Table 2). This result suggested that anomalous synoptic-scale ascending motions to the rear of AANA (i.e., on the back or west side of the anomalous upper-level ridge) had a significant effect on haze pollution in the BTH region. Our results appeared to contradict the speculation by Yin and Wang (2017), who simply concluded that the sinking motion generated by AANA reflected its overall state. The following sections explore how the associated vertical circulation affected severe haze in the BTH region.

The anomalous synoptic-scale ascending motion associated with AANA extended through the depth of the troposphere (Fig. 8). Considering the climatological mean state over the BTH region (i.e., descending motion; Fig. S1 in the Supplement), this anomalous ascent weakened the usual descending motion in the local area when severe haze occurred, occasionally even generating a weak ascending motion in the lower troposphere (i.e., 500-800 hPa; Fig. 9a). Even though the sinking motion still prevailed over the BTH region, descent from the upper levels was greatly weakened due to the anomalous ascent (Fig. 9a). This effect might explain why subsidence and associated adiabatic warming weakened during severe haze episodes and yet did not dominate the changes in lower-level temperature (Fig. 7). The strong warm advection mentioned above (Fig. 7) represented a decline in dry-air intrusions (Sun et al., 2017). As a result, the invasion of cold and dry air from upper levels to the surface was relatively weak, conditions favorable for the formation of severe haze (Sun et al., 2017; Hu et al., 2018). The anomalous ascending motion in the middle troposphere not only weakened the normal sinking motion but also inhibited the downward transport of westerly momentum at mid-levels and upper levels (i.e., $\frac{\partial u \omega}{\partial P}>0$; see Fig. 9b), leading to weaker northerly winds near the surface (Lu et al., 2010; Liu and Guo, 2012). This inhibition of downward momentum flux reflected a reduced frequency of cold-air intrusions (Hu et al., 2018) and also affected the intensity of turbulence. On the one hand, with the weakening of momentum exchange between the upper and lower levels, the transformation of kinetic energy from the basic flow to the turbulent flow was suppressed (Liu and Liu, 2011). On the other hand, the temperature inversion mainly generated by anomalous southeasterly winds led to increased atmospheric stability and dissipation of turbulent kinetic energy. Both of these factors caused the kinetic energy of turbulence to decrease (Liu and Liu, 2011). Weaker turbulence resulted in a shallower planetary boundary layer (Fig. 3a). The PBLH over the BTH region was only $266.7 \mathrm{~m}$ during severe haze episodes (compared to a mean PBLH in December of $430.7 \mathrm{~m}$ based on ERA-Interim data). This had adverse effects on the dispersion of pollutants. The SPCC between the PBLH anomalies and the $\mathrm{PM}_{2.5}$ concentration was -0.60 , passing the $99 \%$ confidence level (Table 2). It is worth noting that the emergence of an inversion in the BTH region resulted in a more stable atmosphere, and thus the aforementioned anomalous ascending motion was isolated from the air lying beneath the stable layer (Corfidi et al., 2008). However, the anomalous vertical motion still contributed to a favorable synoptic-scale environment for haze by confining clean-air intrusions and downward momentum fluxes from upper levels. Once the anomalous ascent weakened, and descending motion again prevailed over the BTH region, the supply of clean air from mid-levels and upper levels helped to break the inversion layer (Fig. 7c). This effect also strengthened the downward flux of momentum, enhancing northerly winds near the surface. Subsequently, the BTH region was mainly controlled by cold advection (Fig. 7c). These factors marked the dissipation process for the haze. For non-haze episodes, the cyclonic circulation induced an anomalous descending motion over the BTH region, which strengthened the local meridional circulation (Fig. 8c-d) and the downward transport of westerly momentum at mid-levels and upper levels (Fig. 9c-d). Under these circumstances, clean-air intrusions from the free troposphere were more fre- 
Table 3. The SPCCs between $\mathrm{AANAI}_{Z_{500}}\left(\mathrm{AANAI}_{V_{850}}, \mathrm{AANAI}_{\omega_{500}}\right)$ and regional meteorological indices.

\begin{tabular}{lrrrrr}
\hline SPCC & Visibility & $\begin{array}{r}\text { Surface wind } \\
\text { speed }\end{array}$ & $\begin{array}{r}\text { Surface } \\
\text { RH }\end{array}$ & $\begin{array}{r}\text { TIP } \\
\text { anomalies }\end{array}$ & $\begin{array}{r}\text { ERA PBLH } \\
\text { anomalies }\end{array}$ \\
\hline AANAI $_{Z_{500}}$ & $-0.71^{\mathrm{b}}$ & $-0.38^{\mathrm{b}}$ & $0.73^{\mathrm{b}}$ & $0.58^{\mathrm{b}}$ & $-0.50^{\mathrm{b}}$ \\
AANAI $_{850}$ & $0.59^{\mathrm{b}}$ & 0.25 & $-0.56^{\mathrm{b}}$ & $-0.41^{\mathrm{b}}$ & $0.40^{\mathrm{b}}$ \\
AANAI $_{\omega_{500}}$ & $0.51^{\mathrm{b}}$ & 0.11 & $-0.50^{\mathrm{b}}$ & $-0.30^{\mathrm{a}}$ & 0.22 \\
\hline
\end{tabular}

a indicates that the SPCC exceeded the $95 \%$ confidence level. ${ }^{b}$ indicates that the SPCC exceeded the $99 \%$ confidence level. SPCCs were calculated based on SPM data, aggregated by averaging all meteorological data and AANA indices during each severe haze (14), non-haze (12), and non-severe haze (24) episode. The total sample size was 50 .

(a) Day-1

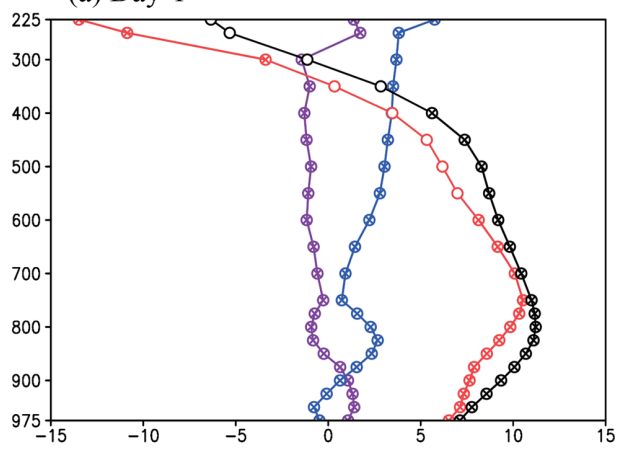

(b) Day+0

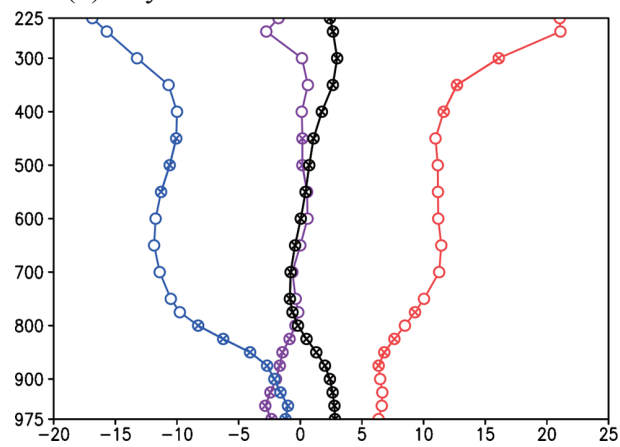

(c) Day+1

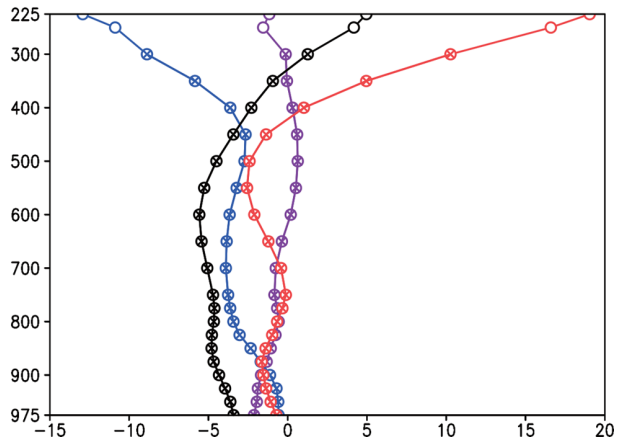

Figure 7. Differences of temperature tendencies (units: $10^{-5} \mathrm{~K} \mathrm{~s}^{-1}$ ) between severe haze and non-haze events over the BTH region. "Day+0" refers to the first day of severe haze and non-haze events. "Day-1" refers to $1 \mathrm{~d}$ before the first day of severe haze and non-haze events. "Day+1" refers to $1 \mathrm{~d}$ after the first day of severe haze and non-haze events. The black line represents local temperature changes (i.e., $\frac{\partial T}{\partial t}$ ). The red line represents horizontal temperature advection (i.e., $-V \cdot \nabla T$ ). The blue line represents the combined effects of adiabatic compression and vertical advection (i.e., $\left(\frac{\kappa T}{P}-\frac{\partial T}{\partial P}\right) \omega, \kappa=R / C_{p}=0.286$; Wallace and Hobbs, 2006). The purple line represents the effect of diabatic heating processes (i.e., $\frac{J}{C_{p}}, J$ represents diabatic heating rate; this term was obtained as a residual). " $\otimes$ " indicates that differences between severe haze and non-haze episodes exceeded the $95 \%$ confidence level ( $t$ test) for that term.

quent and surface wind speeds and turbulent exchange were enhanced, leading to conditions conducive to pollutant dispersion. In general, AANA were accompanied by an anomalous synoptic-scale ascent to its rear, which weakened the normal meridional circulation over the BTH region and restricted clean-air intrusions from higher levels. The resulting weak local vertical circulation also inhibited downward momentum transport and led to lower surface wind speeds, weaker turbulence, and a shallower boundary layer in the lo- cal area. These effects provided a favorable synoptic-scale environment for the formation and development of severe haze.

Note that AANA modulated a thermally indirect zonal circulation between the BTH region and the western Pacific, i.e., ascending motion over land and descending motion over sea, in contrast to the mean state over this region during the boreal winter (ascending motion over the relatively warm sea and descending motion over the relatively cold land; see 
(a) Severe haze

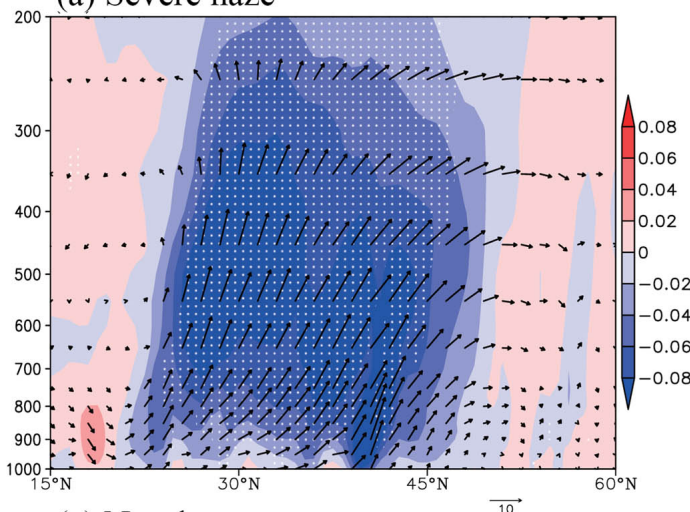

(c) Non-haze

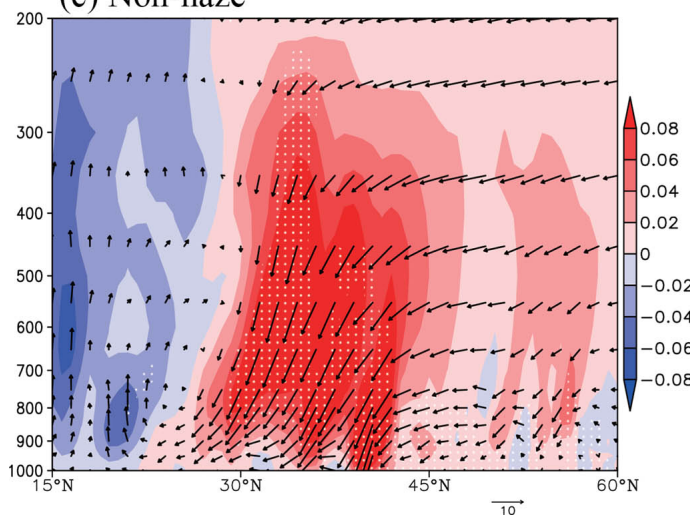

(b) Severe haze

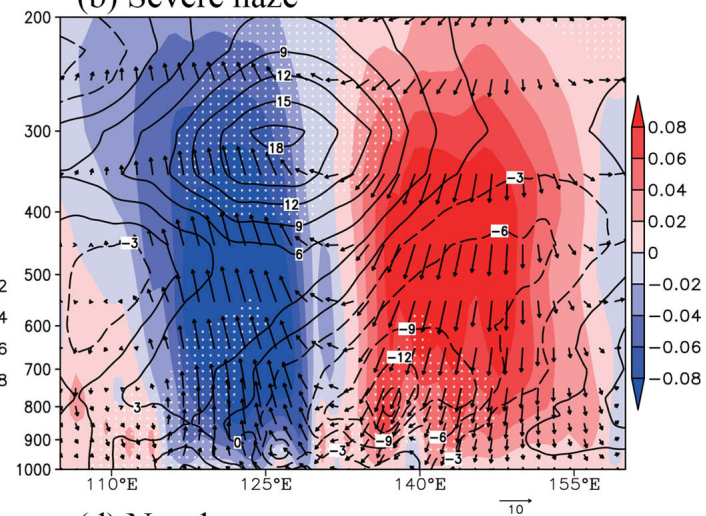

(d) Non-haze

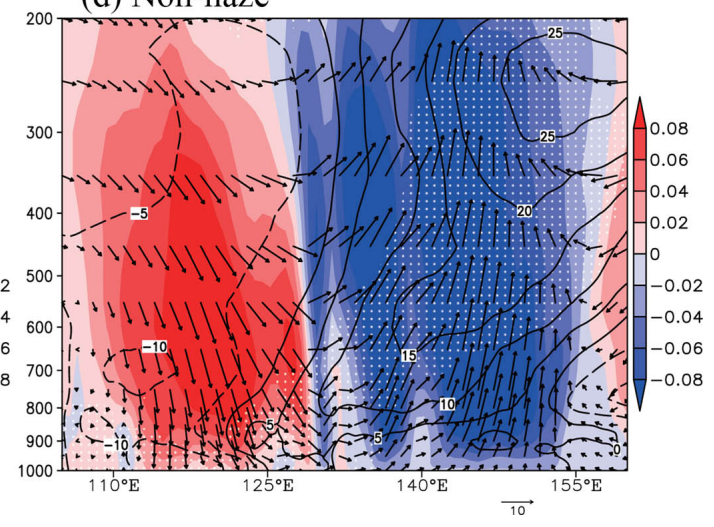

Figure 8. The vertical circulation during severe haze or non-haze episodes (composite anomalies): (a) meridional component of the vertical circulation averaged over AANA (115-125 E) during severe haze episodes (vertical velocity, shading, units: Pa $^{-1}$; vectors represent the vertical and meridional components); white dots indicate that vertical velocity anomalies exceeded the $95 \%$ confidence level $(t$ test). (b) Zonal component of the vertical circulation averaged over AANA $\left(30-40^{\circ} \mathrm{N}\right)$ during severe haze episodes (vertical velocity, shading, units: $\mathrm{Pas}^{-1}$; vectors represent the vertical and zonal components) and $\mathrm{RH}$ anomalies (contour, units: \%); white dots indicate that $\mathrm{RH}$ anomalies exceeded the $95 \%$ confidence level $(t$ test). Panel (c) is the same as (a) but for non-haze episodes. Panel (d) is the same as (b) but for non-haze episodes. Anomalies were calculated with respect to the 1979-2010 climatology. To put the horizontal velocity and the vertical velocity on the same order of magnitude, the vertical velocity (omega) has been magnified 100 times.

Fig. S2). This thermally indirect circulation acted as an important water vapor path (Fig. 8b). Easterly winds in the lower troposphere triggered by AANA brought warm, humid air to the BTH region, resulting in higher $\mathrm{RH}$ in the lower (900-1000 hPa) atmosphere. This effect could accelerate the growth of fine particulates and lead to a sharp increase in the $\mathrm{PM}_{2.5}$ concentration. Higher RH near the surface also limited evaporation, thus restricting the development of turbulence (Betts, 1997). Consequently, anomalous ascent was weak near the surface relative to the anomalies in the lower and middle troposphere. Weak updrafts near the surface reduced the vertical dispersion of pollutants (Sun et al., 2017; Yin and Wang, 2018). Moreover, the aforementioned temperature inversion layer also favored weaker turbulence, which acted against the ascending motion in lower levels connecting with motions at upper levels. During non-haze events, the thermally direct vertical circulation (i.e., ascending motion over sea and descending motion over land) was evident in the AANA region, favoring the transport of pollutants and water vapor to the ocean. The resulting drier atmosphere over the BTH region limited the growth of fine particulates. In brief, the thermally indirect circulation between land and sea modulated by AANA provided a persistent source of water vapor for severe haze, and the resulting higher $\mathrm{RH}$ weakened the turbulence. These effects might explain why severe haze tended to last for a long time.

We further investigated the evolution of AANA composited onto severe haze or non-haze episodes to provide a basis for air quality forecasting. Before severe haze episodes, northeastern Asia was mainly covered by a cyclonic circulation, which had a tendency to weaken over time (Fig. 10ac). This effect was caused by the strengthening of positive geopotential height anomalies over Lake Baikal. The eastward propagation of positive anomalies over Lake Baikal was a precursor signal of severe haze. On the first day of severe haze, AANA were relatively typical: strong at midlevels, with anomalous ascending motion over the BTH region and anomalous southeasterly winds near the surface 
(a) Severe haze

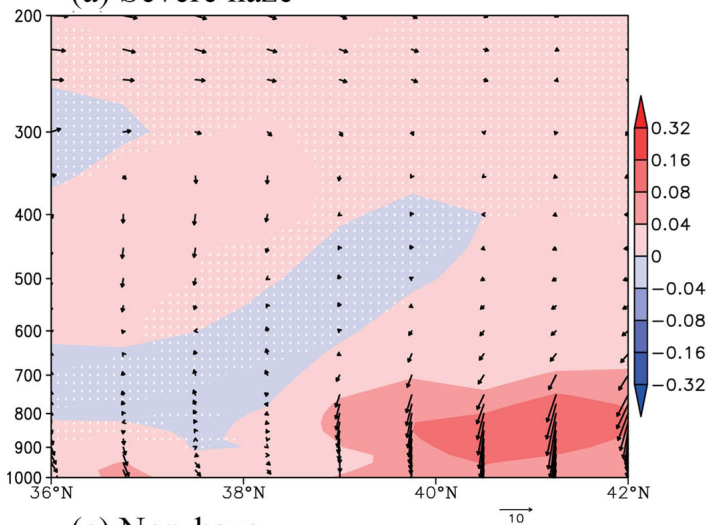

(c) Non-haze

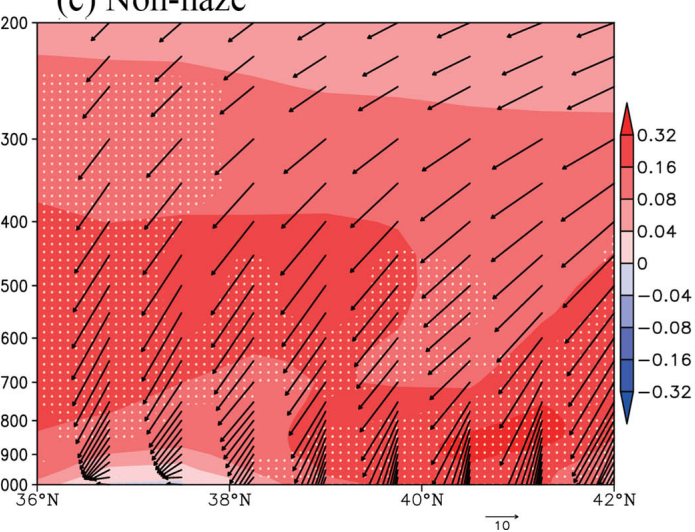

(b) Severe haze

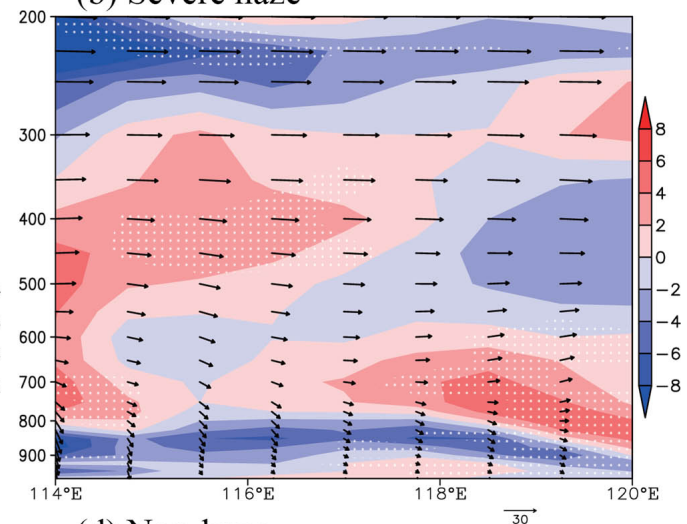

(d) Non-haze

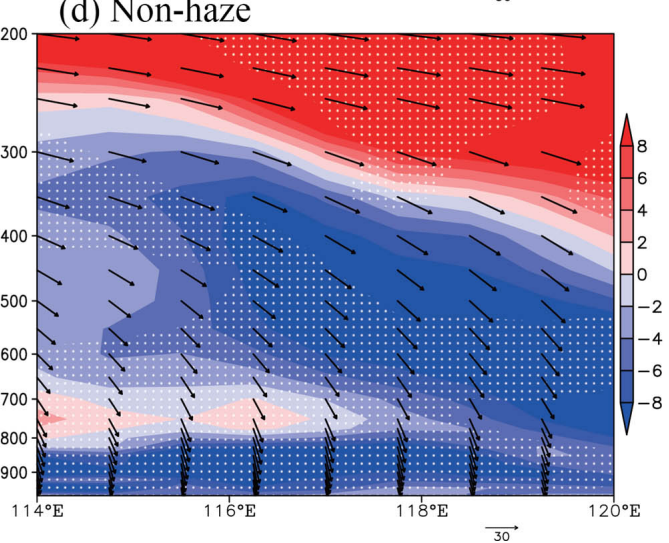

Figure 9. The vertical circulation during severe haze or non-haze episodes (composite synoptic processes): (a) meridional component of the vertical circulation averaged over the BTH region $\left(114-120^{\circ}\right.$ E) during severe haze episodes (vertical velocity, shading, units: Pa ${ }^{-1}$; vectors represent the vertical and meridional components); white dots indicate that vertical velocity exceeded the $95 \%$ confidence level ( $t$ test). (b) Zonal component of the vertical circulation $\left(36-42^{\circ} \mathrm{N}\right)$ during severe haze episodes (vectors represent the vertical and zonal components) and the vertical transport of westerly momentum (shading, units: $10^{-5} \mathrm{~m} \mathrm{~s}^{-2}$ ); white dots indicate that vertical transport of westerly momentum exceeded the $95 \%$ confidence level $(t$ test). Panel (c) is the same as (a) but for non-haze episodes. Panel (d) is the same as (b) but for non-haze episodes. To put the horizontal velocity and the vertical velocity on the same order of magnitude, the vertical velocity (omega) has been magnified 100 times.

(Fig. 10d). These anomalies regulated the synoptic-scale environment and provided favorable conditions for the formation of severe haze. AANA moved to the east continually after the first day of severe haze (Fig. 10e-f). At $3 \mathrm{~d}$ after the onset of severe haze, AANA were replaced by a cyclonic circulation, and haze tended to dissipate (Fig. 10g). The reemergence of a cyclonic circulation over the BTH region marked the end of the severe haze. For non-haze episodes, AANA remained strong and moved slowly before the non-haze day (Fig. 10h-j). The few cyclones that developed were mainly located at high latitudes. The switch from an anticyclonic circulation to a cyclonic system occurred a day before the nonhaze day, associated with cold air entering the BTH region from the north. On the first non-haze day, a cyclonic circulation developed over northeastern Asia (Fig. 10k). An anomalous descending motion over the BTH region and northerly wind near the surface were both evident. A day after the nonhaze day, anomalous descending motions were enhanced due to the development of the cyclonic circulation (Fig. 101). The cyclonic circulation then moved eastward, pushed by the positive anomaly over Lake Baikal (Fig. 10n). In brief, the emergence and development of severe haze (non-haze) was matched by the movement and development of AANA. Thus, AANA could be an effective forecast indicator for air quality.

\section{Conclusion and discussion}

Severe haze in the BTH region has grown both more serious and more persistent in recent years, which has wreaked havoc on society and the economy. Based on the $\mathrm{PM}_{2.5}$ concentration data collected from the air quality measurement network in China, this research focused on severe haze episodes over the BTH region during December in the years 20142016. Non-haze episodes were also taken into account as a comparison. The associated atmospheric circulations and the structure of AANA were analyzed. The results indicated 
(a) Severe haze day-3

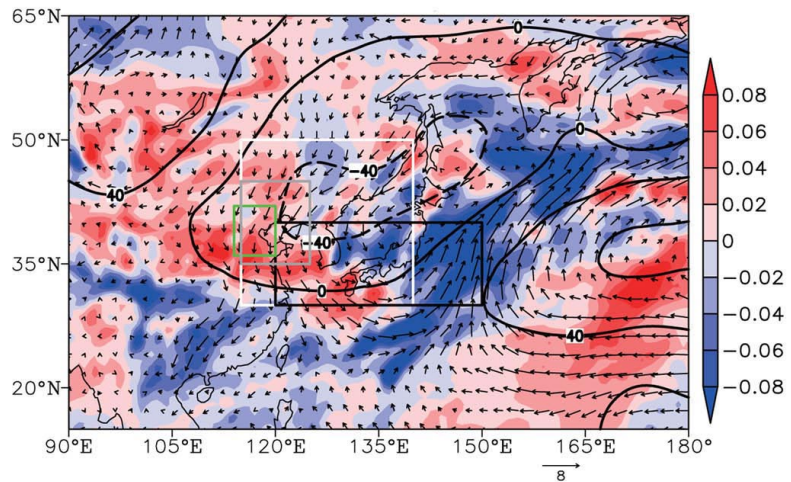

(b) Severe haze day-2

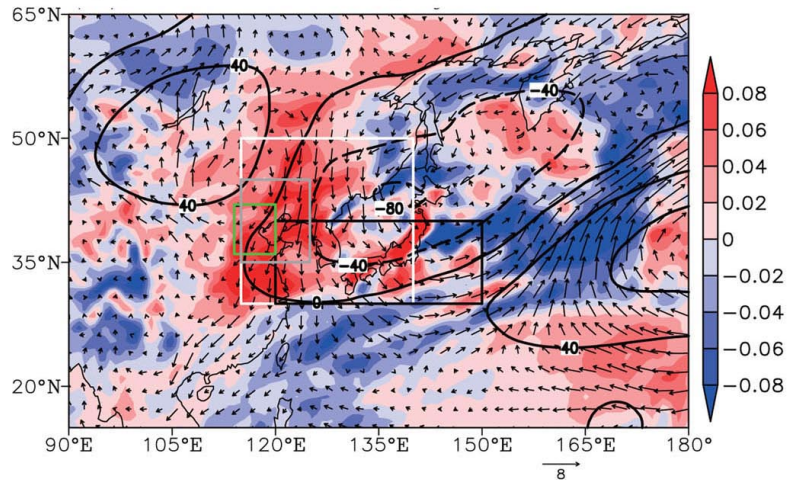

(c) Severe haze day-1

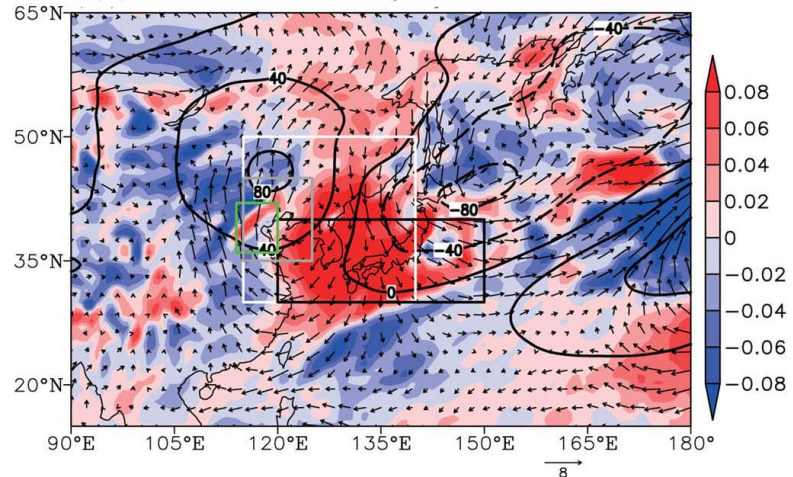

(d) Severe haze day +0

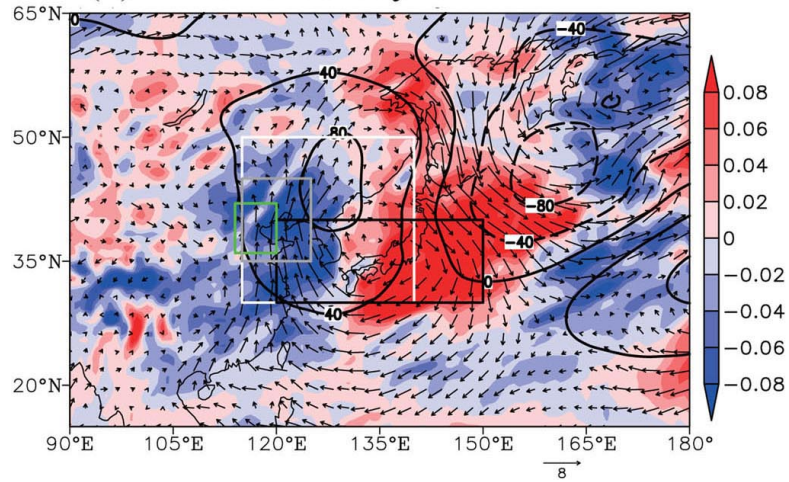

(h) Non-haze day-3

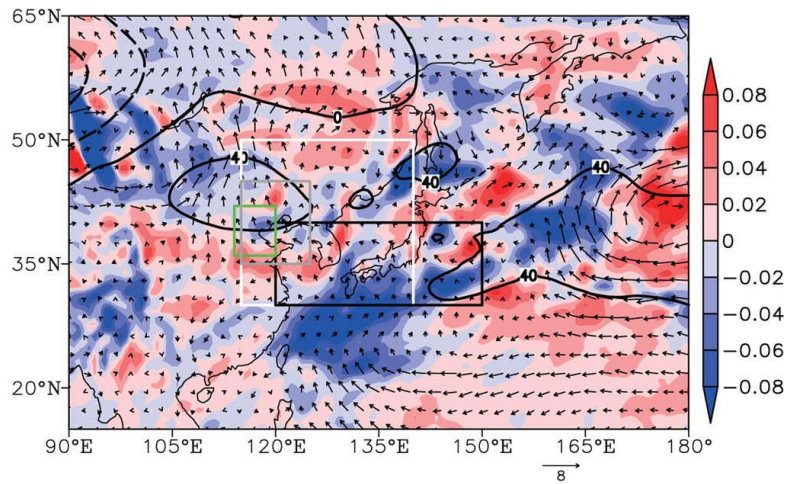

(i) Non-haze day-2

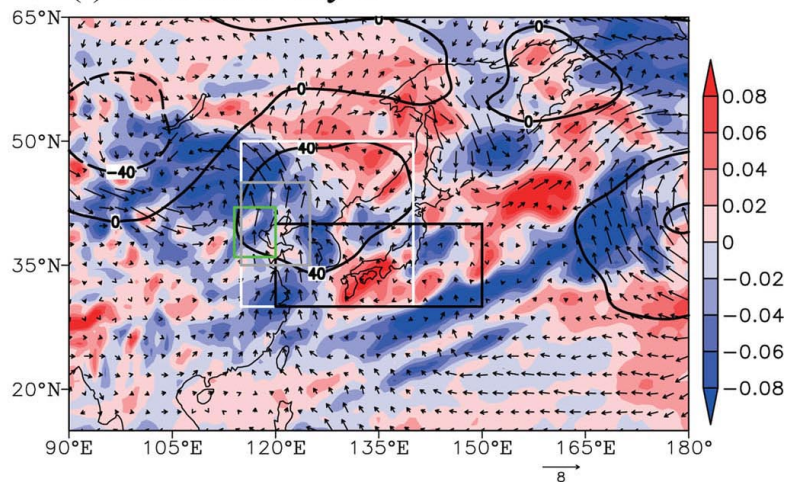

(j) Non-haze day-1

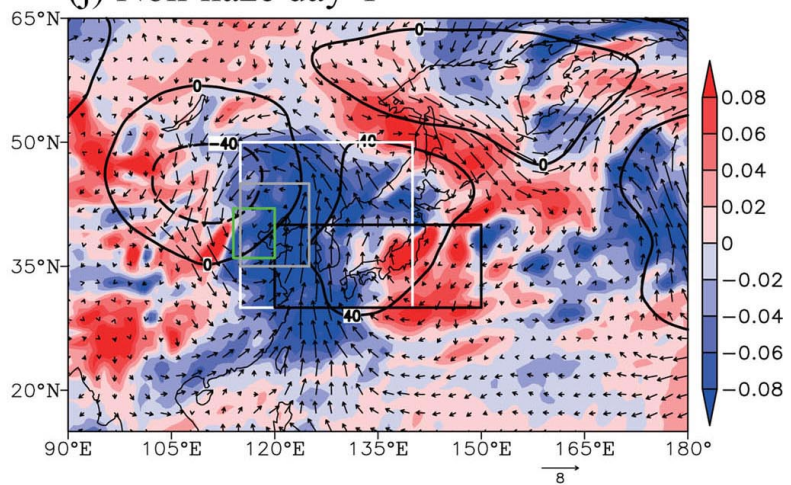

(k) Non-haze day +0

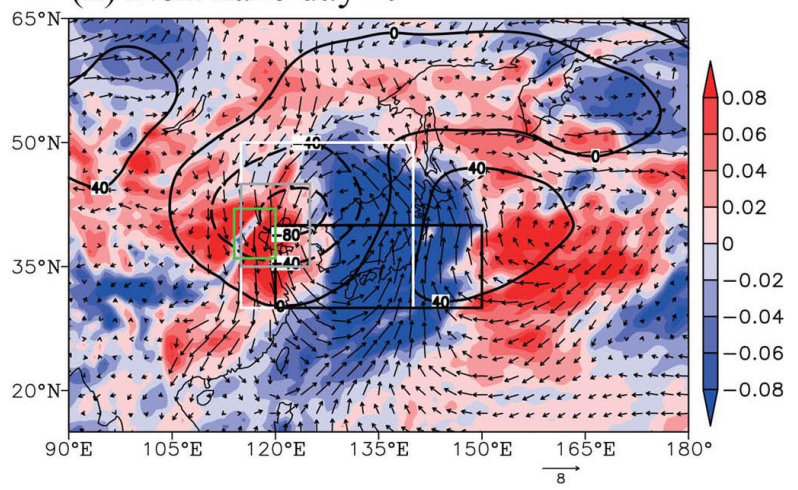

Figure 10. 
(e) Severe haze day+1

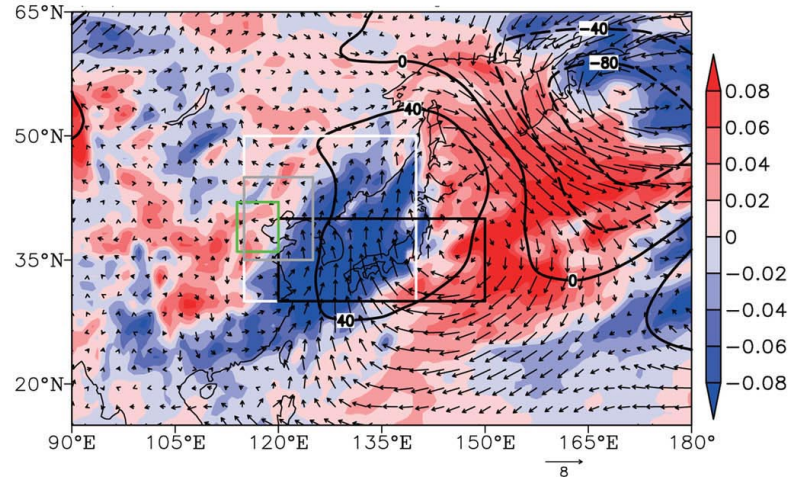

(f) Severe haze day +2

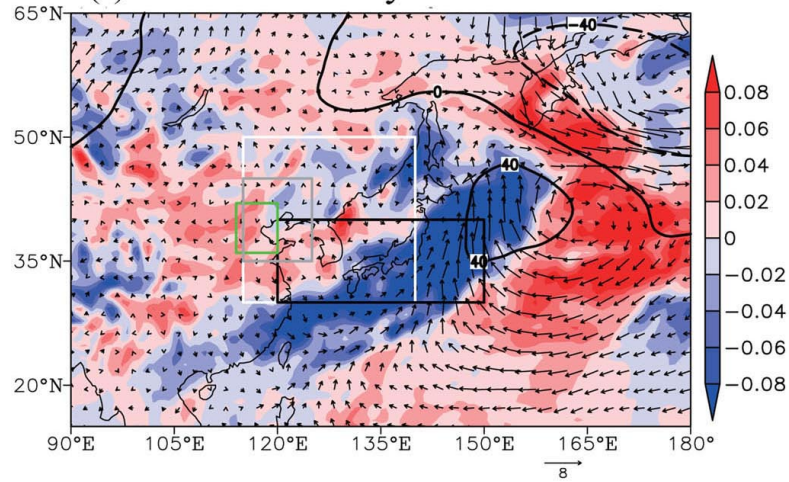

(g) Severe haze day +3

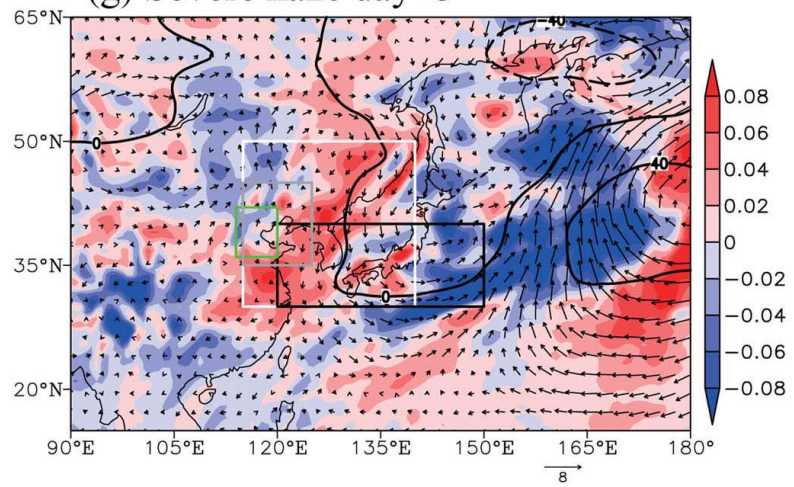

(1) Non-haze day+1

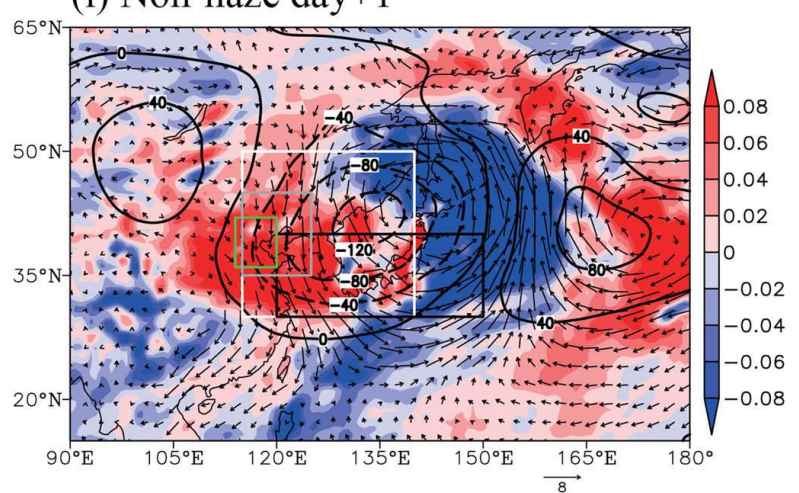

(m) Non-haze day+2

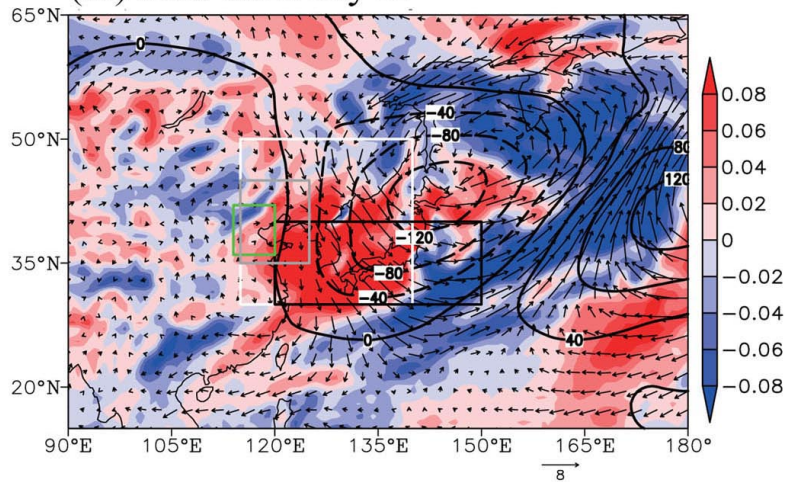

(n) Non-haze day+3

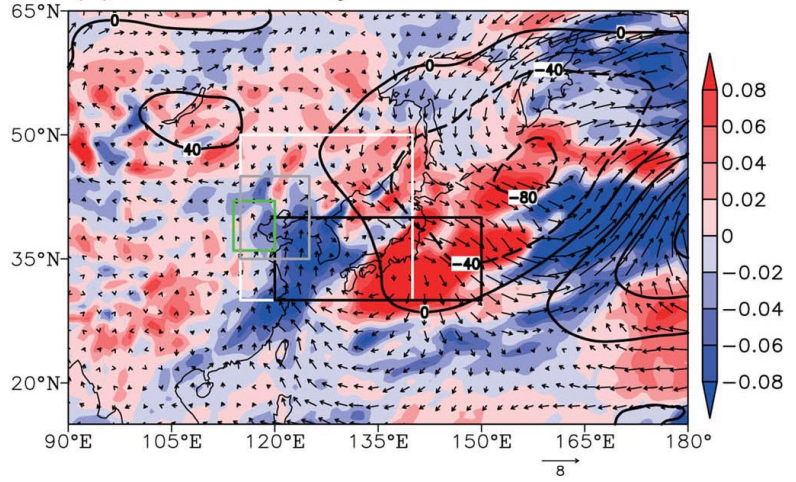

Figure 10. Evolution of AANA during severe haze episodes (a-g) and non-haze episodes (h-n): $Z_{500}$ (contour, units: gpm), $V_{850}($ arrow, units: $\mathrm{m} \mathrm{s}^{-1}$ ), and $\omega_{500}$ (shading, units: Pa s${ }^{-1}$ ). Anomalies were calculated with respect to the 1979-2010 climatology. Severe haze or nonhaze day +0 refers to the first day of severe haze or non-haze. Severe haze (non-haze) day-3, severe haze (non-haze) day-2, and severe haze (non-haze) day-1 refer to 3, 2, and $1 \mathrm{~d}$ before the first day of severe haze (non-haze), respectively. Severe haze (non-haze) day+1, severe haze (non-haze) day +2 , and severe haze (non-haze) day+3 refer to 1, 2, and $3 \mathrm{~d}$ after the first day of severe haze (non-haze), respectively. The green box indicates the BTH region. The white, black, and gray boxes indicate the areas covered by $\mathrm{AANAI}_{Z_{500}}$, AANAI $V_{850}$, and AANAI $_{\omega_{500}}$, respectively.

that AANA were closely related to weaker surface winds, a stronger temperature inversion, a shallower boundary layer, and higher $\mathrm{RH}$ in the $\mathrm{BTH}$ region, which were of importance in the formation of severe haze. AANA motivated southeasterly winds in the lower troposphere and the gathering pollutants and moisture over the BTH region. Strong southeasterly winds also generated a temperature inversion through warm advection, which strengthened the stability of the lower atmosphere. Being synoptic in scale, AANA were accompanied by anomalous vertical motion in the surrounding areas. This weakened the local meridional circulation and reduced the frequency of cold- and dry-air invasions. Meanwhile, the anomalous vertical motion also inhibited the downward transport of momentum and resulted in lower surface wind 
(a) Severe haze

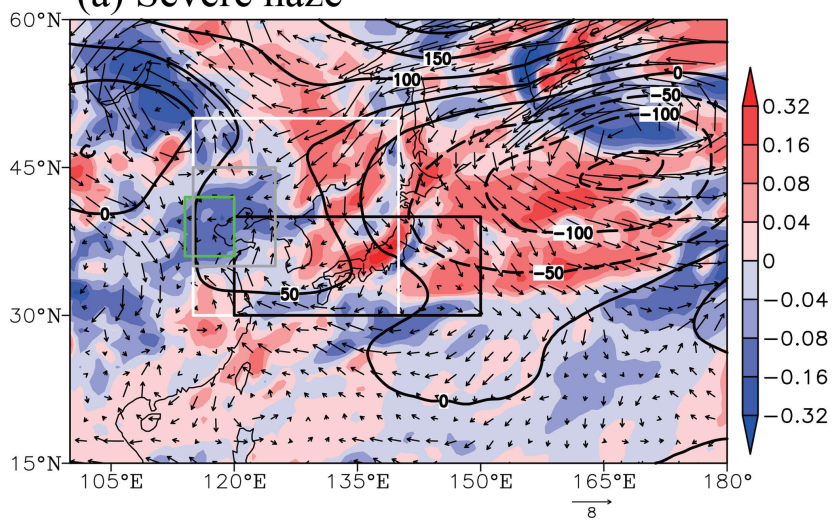

(b) Non-haze

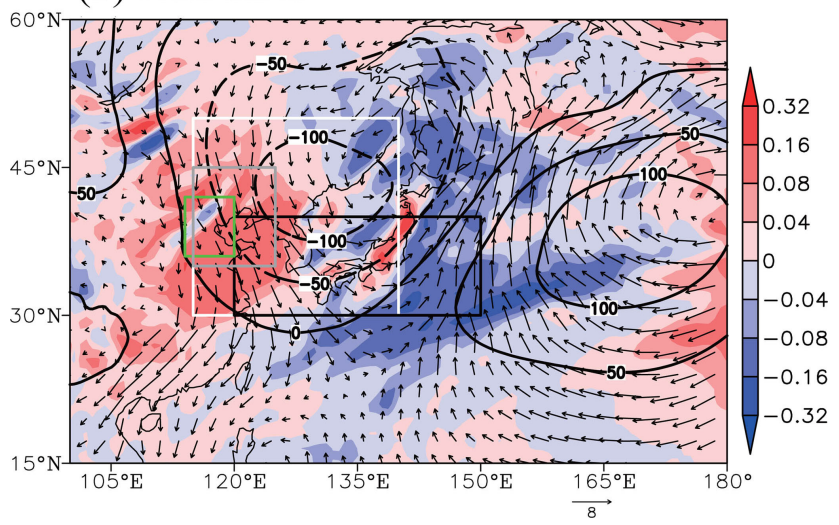

Figure 11. Structure of AANA during (a) severe haze episodes and (b) non-haze episodes in December 2017: $Z_{500}$ (contour, units: gpm), $V_{850}$ (arrow, units: $\mathrm{m} \mathrm{s}^{-1}$ ), and $\omega_{500}$ (shading, units: $\mathrm{Pa} \mathrm{s}^{-1}$ ). Anomalies were calculated with respect to the 1979-2010 climatology. The green box indicates the BTH region. The white, black, and gray boxes indicate the areas covered by $\mathrm{AANAI}_{Z_{500}}, \mathrm{AANAI}_{V_{850}}$, and $\operatorname{AANAI}_{\omega_{500}}$, respectively.

speeds, weaker turbulence, and a shallower boundary layer, which in turn suppressed pollutant dispersion. AANA also modulated a thermally indirect circulation between land and sea, which acted to funnel moisture into the region. Abundant moisture promoted the growth of haze particulates and higher RH weakened turbulence. These factors provided favorable conditions for the emergence and development of severe haze. The evolution of AANA with respect to severe haze and non-haze episodes was also discussed. Positive geopotential height anomalies over Lake Baikal propagated eastward before forming AANA and therefore represented a precursor signal for severe haze. In contrast, a transition from anticyclonic circulation to cyclonic circulation occurred in the lead-up to non-haze days, resulting in the rapid introduction of polar cold air.

It is widely acknowledged that fine PM is the main cause of severe haze in China (Wang et al., 2016; Cai et al., 2017). Compared with the visibility data used in previous research
(Chen and Wang, 2015; Yin et al., 2015a, b), $\mathrm{PM}_{2.5}$ concentrations better represent the characteristics of haze pollution. Thus, the severe and non-haze events analyzed in this research were identified according to $\mathrm{PM}_{2.5}$ concentration, while visibility data were included to draw comparisons with previous research. The basic conclusion that stronger AANA, corresponding to a weaker EAWM, can promote severe haze by generating weaker surface winds, a stronger temperature inversion, and higher $\mathrm{RH}$ is in agreement with previous findings (Yin et al., 2015a; Yin and Wang, 2017). Strong correlations between the AANA indices and visibility also exist (Tables 3 and 5). In addition, this study offers novel insights into the formation of severe haze in the BTH region. Our analysis demonstrated the dynamic mechanism through which AANA affected severe haze in the BTH region. AANA not only motivated southeasterly winds near the surface but also modulated anomalous vertical motion. These synoptic-scale environments led to local meteorological conditions that were conducive to severe haze, including weaker surface winds, a stronger temperature inversion, a shallower boundary layer, and higher RH. The situation in December 2017 backed up our conclusions. Even though the haze events were not as serious as those in previous years, AANA could be detected in the middle troposphere when severe haze occurred (Fig. 11a). The BTH region was covered by anomalous southerly winds near the surface and anomalous ascending motion at upper levels. The strong cyclonic circulation over northeastern Asia might explain why the haze pollution was less severe in December 2017 (Fig. 11b). The relationship between AANA and severe haze in the BTH region expressed different features in different years but remained strong. In 2014, 2016, and 2017, SPCCs between $\mathrm{PM}_{2.5}$ concentrations and $\mathrm{AANAI}_{Z_{500}}$ were $0.81,0.79$, and 0.73 , respectively, all passing the $99 \%$ confidence level (Table 4). These results indicated that AANA could play an important role in the formation of severe haze over the BTH region in 2014, 2016, and 2017. However, the SPCC between the $\mathrm{PM}_{2.5}$ concentration and $\mathrm{AANAI}_{Z_{500}}$ was 0.53 in 2015, failing to pass the confidence test. The weaker correlation might reflect the influence of El Niño-Southern Oscillation on the mid-tropospheric circulation. Although AANA were not evident at mid-levels, they still emerged in the lower troposphere and had an impact on severe haze. The SPCC between the $\mathrm{PM}_{2.5}$ concentration and $\mathrm{AANAI}_{V_{850}}\left(\mathrm{AANAI}_{\omega_{500}}\right)$ was $-0.61(-0.66)$, exceeding the $95 \%$ confidence level (Table 4). In addition, there were some differences in how AANA affected severe haze. In 2014, AANA strengthened the severe haze mainly by enhancing TIP anomalies and surface RH, whose SPCCs with $\mathrm{AANAI}_{Z_{500}}$ were 0.62 and 0.57 , respectively (Table 5). AANA promoted weaker surface winds, higher surface RH, and a shallower boundary layer in 2015. The SPCCs between AANAI $V_{850}$ and surface wind speed, surface RH, and ERA PBLH anomalies were $0.74,-0.70$, and 0.64 , respectively (Table 5). Similar situations were detected in 2016 and 2017 (Table 5). These 
Table 4. SPCCs between the mean $\mathrm{PM}_{2.5}$ concentration over the BTH region and key indices in December 2014, December 2015, December 2016, and December 2017.

\begin{tabular}{rrrrrrrrrr}
\hline SPCC & $\begin{array}{r}\text { AANA } \\
I_{500}\end{array}$ & $\begin{array}{r}\text { AANA } \\
I_{850}\end{array}$ & $\begin{array}{r}\text { AANA } \\
I_{\omega_{500}}\end{array}$ & Visibility & $\begin{array}{r}\text { Surface wind } \\
\text { speed }\end{array}$ & $\begin{array}{r}\text { Surface } \\
\text { RH }\end{array}$ & $\begin{array}{r}\text { TIP } \\
\text { anomalies }\end{array}$ & $\begin{array}{r}\text { ERA PBLH } \\
\text { anomalies }\end{array}$ & $\begin{array}{r}\text { FNL } \\
\text { PBLH }\end{array}$ \\
\hline 2014 & $0.81^{\mathrm{b}}$ & $-0.72^{\mathrm{b}}$ & $-0.77^{\mathrm{b}}$ & $-0.76^{\mathrm{b}}$ & -0.36 & $0.75^{\mathrm{b}}$ & $0.69^{\mathrm{b}}$ & $-0.65^{\mathrm{b}}$ & \\
2015 & 0.53 & $-0.61^{\mathrm{a}}$ & $-0.66^{\mathrm{a}}$ & $-0.94^{\mathrm{b}}$ & $-0.53^{\mathrm{a}}$ & $0.92^{\mathrm{b}}$ & 0.37 & $-0.63^{\mathrm{a}}$ & $-0.72^{\mathrm{b}}$ \\
2016 & $0.79^{\mathrm{b}}$ & $-0.62^{\mathrm{b}}$ & $-0.70^{\mathrm{b}}$ & $-0.9^{\mathrm{b}}$ & $-0.52^{\mathrm{a}}$ & $0.87^{\mathrm{b}}$ & $0.80^{\mathrm{b}}$ & $-0.63^{\mathrm{b}}$ & $-0.70^{\mathrm{b}}$ \\
2017 & $0.73^{\mathrm{b}}$ & -0.33 & $-0.58^{\mathrm{a}}$ & $-0.89^{\mathrm{b}}$ & $-0.68^{\mathrm{b}}$ & $0.86^{\mathrm{b}}$ & $0.68^{\mathrm{b}}$ & $-0.73^{\mathrm{b}}$ & $-0.68^{\mathrm{b}}$ \\
\hline
\end{tabular}

${ }^{a}$ indicates that the SPCC exceeded the $95 \%$ confidence level. ${ }^{b}$ indicates that the SPCC exceeded the $99 \%$ confidence level. Synoptic-process correlation coefficients (SPCCs) were calculated based on the SPM data, aggregated by averaging mean $\mathrm{PM}_{2.5}$ concentrations, all meteorological data, and AANA indices during each severe haze, non-haze, and non-severe haze episode. The sample sizes in 2014, 2015, 2016, and 2017 were 18, 14, 18, and 15, respectively. Note that PBLH estimates from the FNL dataset are only available after 2015.

Table 5. SPCCs between $\mathrm{AANAI}_{Z_{500}}\left(\mathrm{AANAI}_{V_{850}}, \mathrm{AANAI}_{\omega_{500}}\right)$ and regional meteorological indices in December 2014, December 2015, December 2016, and December 2017.

\begin{tabular}{|c|c|c|c|c|c|c|c|}
\hline Year & SPCC & Visibility & $\begin{array}{r}\text { Surface wind } \\
\text { speed }\end{array}$ & $\begin{array}{r}\text { Surface } \\
\text { RH }\end{array}$ & $\begin{array}{r}\text { TIP } \\
\text { anomalies }\end{array}$ & $\begin{array}{r}\text { ERA PBLH } \\
\text { anomalies }\end{array}$ & $\begin{array}{r}\text { FNL } \\
\text { PBLH }\end{array}$ \\
\hline \multirow[t]{3}{*}{2014} & $\mathrm{AANAI}_{Z_{500}}$ & $-0.64^{b}$ & -0.10 & $0.57^{\mathrm{a}}$ & $0.62^{b}$ & -0.39 & \\
\hline & AANAI $_{V_{850}}$ & 0.35 & -0.09 & -0.38 & -0.27 & 0.22 & \\
\hline & $\operatorname{AANAI}_{\omega 500}$ & 0.46 & -0.01 & -0.45 & -0.45 & 0.27 & \\
\hline \multirow[t]{3}{*}{2015} & $\mathrm{AANAI}_{Z_{500}}$ & $-0.66^{\mathrm{a}}$ & $-0.68^{b}$ & $0.64^{\mathrm{a}}$ & 0.07 & -0.46 & $-0.65^{\mathrm{a}}$ \\
\hline & AANAI $_{V_{850}}$ & $0.75^{\mathrm{b}}$ & $0.74^{\mathrm{b}}$ & $-0.70^{\mathrm{b}}$ & -0.22 & $0.64^{\mathrm{a}}$ & $0.72^{b}$ \\
\hline & $\operatorname{AANAI}_{\omega_{500}}$ & $0.67^{\mathrm{b}}$ & 0.35 & $-0.79^{b}$ & -0.24 & 0.28 & 0.46 \\
\hline \multirow[t]{3}{*}{2016} & $\mathrm{AANAI}_{Z_{500}}$ & $-0.70^{b}$ & -0.46 & $0.69^{b}$ & $0.67^{b}$ & $-0.53^{\mathrm{a}}$ & $-0.56^{\mathrm{a}}$ \\
\hline & AANAI $_{V_{850}}$ & $0.69^{\mathrm{b}}$ & 0.46 & $-0.60^{\mathrm{b}}$ & $-0.56^{\mathrm{a}}$ & 0.47 & $0.60^{\mathrm{b}}$ \\
\hline & $\mathrm{AANAI}_{\omega 500}$ & $0.64^{\mathrm{b}}$ & 0.26 & $-0.80^{\mathrm{b}}$ & -0.45 & 0.20 & $0.55^{\mathrm{a}}$ \\
\hline \multirow[t]{3}{*}{2017} & $\mathrm{AANAI}_{Z_{500}}$ & $-0.74^{b}$ & $-0.57^{\mathrm{a}}$ & $0.65^{b}$ & $0.72^{b}$ & $-0.66^{b}$ & $-0.59^{a}$ \\
\hline & AANAI $_{V_{850}}$ & 0.17 & 0.03 & 0.01 & 0.16 & 0.12 & 0.05 \\
\hline & AANAI $_{\omega 500}$ & 0.48 & 0.40 & -0.39 & -0.41 & $0.62^{\mathrm{a}}$ & $0.58^{\mathrm{a}}$ \\
\hline
\end{tabular}

${ }^{a}$ indicates that the SPCC exceeded the $95 \%$ confidence level. ${ }^{b}$ indicates that the SPCC exceeded the $99 \%$ confidence level. Synoptic-process correlation coefficients (SPCCs) were calculated based on SPM data, aggregated by averaging all meteorological data and AANA indices during each severe haze, non-haze, and non-severe haze episode. The sample sizes in 2014, 2015, 2016, and 2017 were 18, 14, 18, and 15, respectively. Note that PBLH estimates from the FNL dataset are only available after 2015.

results prove that the AANA indices could capture the relationship between severe haze in the BTH region and the synoptic-scale environment. It is worth noting that the tendency for ERA-Interim to underestimate PBLH (von Engeln and Teixeira, 2013) may be less of an issue during winter over northern China (Guo et al., 2016). We have further calculated SPCCs between the AANA indices and FNL PBLH (Table 5), which indicate that our conclusions are not dependent on the reanalysis dataset. The composite evolution of AANA during severe haze or non-haze episodes illustrated that the intensity of AANA could play an important role in the emergence and dissipation of severe haze. However, the severe haze or non-haze events analyzed in this study were limited to December in the years 2014-2016. Further analysis containing more sample data is required to confirm whether and under what conditions the three AANA indices we defined in this study could be reliable forecast indicators.
Data availability. The ground observations are available from the following website: http://data.cma.cn/ (last access: 25 October 2018; CMA, 2018). Hourly $\mathrm{PM}_{2.5}$ concentration data are available from the following website: http://beijingair.sinaapp. com/ (last access: 25 October 2018; China National Environmental Monitoring Center, 2018). Atmospheric data are available from the ERA-Interim website: https://www.ecmwf.int/ en/forecasts/datasets/reanalysis-datasets/era-interim (last access: 25 January 2019; ERA-Interim, 2019). The FNL PBLH data are available from the NCEP/NCAR data archive: https://rda.ucar.edu/ datasets/ds084.4/ (last access: 25 January 2019; NCEP, 2019). The atmospheric composition data are available from the authors upon request.

Supplement. The supplement related to this article is available online at: https://doi.org/10.5194/acp-19-5941-2019-supplement. 
Author contributions. ZY and HW designed the research. WZ and $\mathrm{ZY}$ performed most of the analysis. WZ prepared the paper with contributions from all co-authors.

Competing interests. The authors declare that they have no conflict of interest.

Acknowledgements. This research was supported by the National Natural Science Foundation of China (41705058 and 91744311), the Natural Science Foundation of Jiangsu Higher Education Institutions of China (17KJB170014), the funding of Jiangsu innovation and entrepreneurship team, and the 2017 Jiangsu Province College Students Innovation and Entrepreneurship Training Program (201710300007).

Review statement. This paper was edited by Joshua Fu and reviewed by two anonymous referees.

\section{References}

Betts, A. K.: The Parameterization of Deep Convection, in: The Physics and Parameterization of Moist Atmospheric Convection, Springer, the Netherlands, 255-279, 1997.

Cai, W. J., Li, K., Liao, H., Wang, H. J., and Wu, L. X.: Weather conditions conducive to Beijing severe haze more frequent under climate change, Nat. Clim. Change, 7, 257-262, https://doi.org/10.1038/nclimate3249, 2017.

Chen, H. P. and Wang, H. J.: Haze Days in North China and the associated atmospheric circulations based on daily visibility data from 1960 to 2012, J. Geophys. Res., 120, 5895-5909, https://doi.org/10.1002/2015JD023225, 2015.

China National Environmental Monitoring Center: Site-observed surface hourly $\mathrm{PM}_{2.5}$ concentration across China, available at: http://beijingair.sinaapp.com/, last access: 25 October 2018.

CMA: Ground observations, available at: http://data.cma.cn/, last access: 25 October 2018.

Corfidi, S. F., Corfidi, S. J., and Schultz, D. M.: Elevated Convection and Castellanus: Ambiguities, Significance, and Questions, Weather Forecast., 23, 1280-1303, https://doi.org/10.1175/2008WAF2222118.1, 2008.

Dee, D. P., Uppala, S. M., Simmons, A. J., Berrisford, P., Poli, P., Kobayashi, S., Andrae, U., Balmaseda, M. A., Balsamo, G., Bauer, P., Bechtold, P., Beljaars, A. C. M., van de Berg, L., Bidlot, J., Bormann, N., Delsol, C., Dragani, R., Fuentes, M., Geer, A. J., Haimberger, L., Healy, S. B., Hersbach, H., Hólm, E. V., Isaksen, L., Kållberg, P., Köhler, M., Matricardi, M., McNally, A. P., Monge-Sanz, B. M., Morcrette, J.-J., Park, B.-K., Peubey, C., de Rosnay, P., Tavolato, C., Thépaut, J.-N., and Vitart, F.: The ERA-Interim reanalysis: configuration and performance of the data assimilation system, Q. J. Roy. Meteor. Soc., 137, 553-597, https://doi.org/10.1002/qj.828, 2011.

Ding, Y. H. and Liu, Y. J.: Analysis of long-term variations of fog and haze in China in recent 50 years and their relations with atmospheric humidity, Sci. China Earth Sci., 57, 36-46, https://doi.org/10.1007/s11430-013-4792-1, 2014.
ERA-Interim: Reanalysis data, available at: http://www.ecmwf.int/ en/research/climate-reanalysis/era-interim, last access: 25 January 2019.

"Formation Mechanism and Control Strategies of Haze in China" professional group: Assessment report on PM_(2.5) control effects in the Beijing-Tianjin-Hebei region since the implement of Air Pollution Prevention and Control Action Plan, Bull. Chin. Acad. Sci., 30, 668-678, https://doi.org/10.16418/j.issn.10003045.2015.05.012, 2015 (in Chinese).

Guo, J., Miao, Y., Zhang, Y., Liu, H., Li, Z., Zhang, W., He, J., Lou, M., Yan, Y., Bian, L., and Zhai, P.: The climatology of planetary boundary layer height in China derived from radiosonde and reanalysis data, Atmos. Chem. Phys., 16, 13309-13319, https://doi.org/10.5194/acp-16-13309-2016, 2016.

He, S. P. and Wang, H. J.: An Integrated East Asian Winter Monsoon Index and Its Interannual Variability, Chinese J. Atmos. Sci., 36, 523-538, https://doi.org/10.3878/j.issn.10069895.2011.11083, 2012 (in Chinese).

Hu, B., Chen, R., Xu, J. X., Yang, G. S., Xu, D. D., Chen, C. Y., and Zhao, Y. L.: Health effects of ambient ultrafine (nano) particles in haze, Chinese Sci. Bull., 60, 2808-2823, https://doi.org/10.1360/N972014-01404, 2015 (in Chinese).

Hu, Y. L., Wang, S. G., Ning, G. C., Zhang, Y., Wang, J. C., and Shang, Z. W.: A quantitative assessment of the air pollution purification effect of a super strong cold-air outbreak in January 2016 in China, Air Qual. Atmos. Hlth., 11, 907-923, https://doi.org/10.1007/s11869-018-0592-2, 2018.

Lackmann, G.: Midlatitude synoptic meteorology: dynamics, analysis, and forecasting, American Meteorological Society, Boston, America, 5-10, 2011.

Li, Q., Zhang, R. H., and Wang, Y.: Interannual variation of the winter-time fog-haze days across central and eastern China and its relation with East Asian winter monsoon, Int. J. Climatol., 36, 346-354, https://doi.org/10.1002/joc.4350, 2015.

Liu, S. K. and Liu, S. D.: Atmospheric dynamics, 2nd Edn., Peking University Press, Beijing, China, 143-147, 2011.

Liu, X. E. and Guo, X. L.: Role of Downward Momentum Transport in the Formation of Severe Surface Winds, Atmos. Ocean. Sci. Lett., 5, 379-383, https://doi.org/10.1080/16742834.2012.11447020, 2012.

Lu, C. S., Niu, S. J., Yang, J., Liu, X., and Zhao, L. J.: Jump Features and Causes of Macro and Microphysical Structures of a Winter Fog in Nanjing, Chinese J. Atmos. Sci., 34, 681690, https://doi.org/10.3878/j.issn.1006-9895.2010.04.02, 2010 (in Chinese).

NCEP: NCEP GDAS/FNL Global Surface Flux Grids: PBLH data, available at: https://rda.ucar.edu/datasets/ds084.4/, last access: 25 January 2019.

Shen, L., Jacob, D. J., Mickley, L. J., Wang, Y., and Zhang, Q.: Insignificant effect of climate change on winter haze pollution in Beijing, Atmos. Chem. Phys., 18, 17489-17496, https://doi.org/10.5194/acp-18-17489-2018, 2018.

Sun, X. C., Han, Y. Q., Li, J., Kang, G. H., and Wan, M. B.: Analysis of the Influence of Vertical Movement on the Process of Fog and Haze with Air Pollution, Plateau Meteor., 36, 1106-1114, 2017 (in Chinese).

Tang, B. Y., Xin, J. Y., Gao, W. K., Shao, P., SU, H. J., Wen, T. X., Song, T., Fan, G. Z., Wang, S. G., and Wang, Y. S.: Characteristics of complex air pollution in typical 
cities of North China, Atmos. Ocean. Sci. Lett., 11, 29-36, https://doi.org/10.1080/16742834.2018.1394158, 2018.

von Engeln, A. and Teixeira, J.: A planetary boundary layer height climatology derived from ECMWF reanalysis data, J. Climate, 26, 6575-6590, https://doi.org/10.1175/JCLI-D-1200385.1, 2013.

Wallace, J. M. and Hobbs, P. V.: Atmospheric science: an introductory survey, 2nd Edn., Elsevier Academic Press, Amsterdam, 283 pp., 2006.

Wang, G. H., Zhang, R. Y., Gomez, M. E., Yang, L. X., Zamora, M. L., Hu, M., Lin, Y., Peng, J. F., Guo, S., Meng, J. J., Li, J. J., Cheng, C. L., Hu, T. F., Ren, Y. Q., Wang, Y. S., Gao, J., Cao, J. J., An, Z. S., Zhou, W. J., Li, G. H., Wang, J. Y., Tian, P. F., Marrero-Ortiz, W., Secrest, J., Du, Z. F., Zheng, J., Shang, D. J., Zeng, L. M., Shao, M., Wang, W. G., Huang, Y., Wang, Y., Zhu, Y. J., Li, Y. X., Hu, J. X., Pan, B., Cai, L., Cheng, Y. T., Ji, Y. M., Zhang, F., Rosenfeld, D., Liss, P., Duce, R., Kolb, C., and Molina, M.: Persistent sulfate formation from London Fog to Chinese haze, P. Natl. Acad. Sci. USA, 113, 13630-13635, https://doi.org/10.1073/pnas.1616540113, 2016.

Wang, H. J.: On assessing haze attribution and control measures in China, Atmos. Ocean. Sci. Lett., 11, 120-122, https://doi.org/10.1080/16742834.2018.1409067, 2018.

Wang, H. J. and Jiang, D. B.: A new East Asian winter monsoon intensity index and atmospheric circulation comparison between strong and weak composite, Quaternary Sci., 24, 1927, https://doi.org/10.3321/j.issn:1001-7410.2004.01.003, 2004 (in Chinese).

Wang, H. J., Chen, H. P., and Liu, J. P.: Arctic sea ice decline intensified haze pollution in eastern China, Atmos. Ocean. Sci. Lett., 8, 1-9, https://doi.org/10.3878/AOSL20140081, 2015.

Wang, Y. S., Yao, L., Liu, Z. R., Ji, D. S., Wang, L. L., and Zhang, J. K.: Formation of haze pollution in Beijing-Tianjin-Hebei region and their control strategies, Bull. Chin. Acad. Sci., 28, 353363, https://doi.org/10.3969/j.issn.1000-3045.2013.03.009, 2013 (in Chinese).

Wei, Y., Li, J., Wang, Z. F., Chen, H. S., Wu, Q. Z., Li, J. J., Wang, Y. L., and Wang, W.: Trends of surface $\mathrm{PM}_{2.5}$ over BeijingTianjin-Hebei in 2013-2015 and their causes: emission controls vs. meteorological conditions, Atmos. Ocean. Sci. Lett., 10, 276283, https://doi.org/10.1080/16742834.2017.1315631, 2017.

Wu, P., Ding, Y. H., Liu, Y. J., and Li, X. C.: Influence of the East Asian winter monsoon and atmospheric humidity on the wintertime haze frequency over central-eastern China, Acta Meteorol. Sin., 74, 352-366, https://doi.org/10.11676/qxxb2016.029, 2016 (in Chinese).

Wu, P., Ding, Y. H., and Liu, Y. J.: Atmospheric circulation and dynamic mechanism for persistent haze events in the Beijing-Tianjin-Hebei region, Adv. Atmos. Sci., 34, 429-440, https://doi.org/10.1007/s00376-016-6158-z, 2017.

Yang, T., Sun, Y. L., Zhang, W., Wang, Z. F., and Wang, X. Q.: Chemical characterization of submicron particles during typical air pollution episodes in spring over Beijing, Atmos. Ocean. Sci. Lett., 9, 255-262, https://doi.org/10.1080/16742834.2016.1173509, 2016.
Yin, Z. and Wang, H.: Role of atmospheric circulations in haze pollution in December 2016, Atmos. Chem. Phys., 17, 1167311681, https://doi.org/10.5194/acp-17-11673-2017, 2017.

Yin, Z. and Wang, H.: The strengthening relationship between Eurasian snow cover and December haze days in central North China after the mid-1990s, Atmos. Chem. Phys., 18, 4753-4763, https://doi.org/10.5194/acp-18-4753-2018, 2018.

Yin, Z., Wang, H., and Chen, H.: Understanding severe winter haze events in the North China Plain in 2014: roles of climate anomalies, Atmos. Chem. Phys., 17, 1641-1651, https://doi.org/10.5194/acp-17-1641-2017, 2017.

Yin, Z. C. and Wang, H. J.: The relationship between the subtropical Western Pacific SST and haze over NorthCentral North China Plain, Int. J. Climatol., 36, 3479-3491, https://doi.org/10.1002/joc.4570, 2016.

Yin, Z. C., Wang, H. J., and Yuan, D. M.: Interdecadal increase of haze in winter over North China and the Huang-huai Area and the weakening of the East Asia Winter Monsoon, Chinese Sci. Bull., 60, 1395-1400, https://doi.org/10.1360/N972014-01348, 2015a (in Chinese).

Yin, Z. C., Wang, H. J., and Guo, W. L.: Climatic change features of fog and haze in winter over North China and Huang-Huai Area, Sci. China Earth Sci., 58, 1370-1376, https://doi.org/10.1007/s11430-015-5089-3, 2015 b.

Zhang, R. H., Li, Q., and Zhang, R. N.: Meteorological conditions for the persistent severe fog and haze event over eastern China in January 2013, Sci. China Earth Sci., 57, 26-35, https://doi.org/10.1007/s11430-013-4774-3, 2014 (in Chinese).

Zhang, X. Y., Sun, J. Y., Wang, Y. Q., Li, W. J., Zhang, Q., Wang, W. G., Quan, J. N., Cao, G. L., Wang, J. Z., Yang, Y. Q., and Zhang, Y. M.: Factors contributing to haze and fog in China, Chinese Sci. Bull., 58, 1178-1187, https://doi.org/10.1360/972013-150, 2013 (in Chinese).

Zhang, Y. J., Zhang, P. Q., Wang, J., Qu, E. S., Liu, Q. F., and Li, G.: Climatic Characteristics of Persistent Haze Events over Jingjinji During 1981-2013, Meteor. Mon., 41, 311-318, https://doi.org/10.7519/j.issn.1000-0526.2015.03.006, 2015 (in Chinese).

Zhao, X. J., Zhao, P. S., Xu, J., Meng,, W., Pu, W. W., Dong, F., He, D., and Shi, Q. F.: Analysis of a winter regional haze event and its formation mechanism in the North China Plain, Atmos. Chem. Phys., 13, 5685-5696, https://doi.org/10.5194/acp13-5685-2013, 2013.

Zhong, Z., Yuan, H. H., Li, J., and Fan, H. Y.: Characteristics of meso-scale perturbation and momentum transportation associated with an intensification process of upper-level jet, Scientia Meteor. Sinica, 30, 639-645, 2010 (in Chinese). 